\title{
Review \\ Sublethal effects of temperature on freshwater organisms, with special reference to aquatic insects
}

\author{
HF Dallas ${ }^{1,2}$ and V Ross-Gillespie ${ }^{3}$ \\ Nelson Mandela Metropolitan University, PO Box 77000, Port Elizabeth 6031, South Africa \\ ${ }^{2}$ Freshwater Research Centre, PO Box 43966, Scarborough 7975, South Africa \\ ${ }^{3}$ Freshwater Research Unit, University of Cape Town, Private Bag X3, Rondebosch 7700, South Africa
}

\begin{abstract}
Water temperature is a key variable affecting aquatic organisms. Understanding their response to elevated water temperatures is important for estimating upper thermal limits, and ultimately for assisting with setting defendable, biologically-relevant water temperature guidelines for lotic systems. Sublethal effects impacting on an individual organism or species may manifest at higher levels of the hierarchy, namely, populations, communities and entire ecosystems. Sublethal effects typically include those affecting an organism's physiology and metabolism (e.g. growth rates, secondary productivity, respiration); phenology (e.g. development time, voltinism, emergence); reproductive success and fitness (e.g. fecundity, rates and success of egg development and hatching); behaviour (e.g. migration, movement, drift); and broad-scale ecological effects (e.g. species richness, composition, density, distribution patterns). Sublethal effects are discussed with examples drawn from freshwater studies, in particular those focused on aquatic insects. Commonly-used methods, which vary from simple, cost-effective, laboratory-based methods to more elaborate, expensive, laboratory- and field-based studies, are assimilated to serve as a toolbox for future thermal research. Ultimately, the method adopted depends largely on the question(s) being asked and available resources.
\end{abstract}

Keywords: biotic responses, experimental, riverine ecosystems, thermal research, tolerance

\section{INTRODUCTION}

Water temperature is an important abiotic driver of aquatic ecosystems influencing many aspects of an organism's existence including its feeding, metabolic and growth rates, fecundity, emergence, behaviour and ultimately survival (see Caissie, 2006; Dallas, 2008; Webb et al., 2008 for reviews). All organisms have a preferred range of temperatures, often termed the 'optimum thermal regime' (Vannote and Sweeney, 1980), at which optimal growth, reproduction and other measures of 'health' are greatest (Dallas and Day, 2004). This optimum range is bounded by the thermal tolerance range (i.e. the range over which a species may survive) with upper and lower tolerance limits demarcating the thermal extremes. Organisms of a given species may survive on either side of this optimal range but as the tolerance limits are approached, signs of stress become evident. The first signs of thermal stress are usually behavioural with avoidance of suboptimal conditions, followed by physiological stress (e.g. respiratory, metabolic or excretory rates may increase), reduction in egg and/or sperm production and hence in fecundity, and increased susceptibility to parasites and pathogens and also to food shortages. Effects are often cumulative and may vary with life stage. Ultimately, biological responses to alterations in water temperature may include changes in individual life history patterns, species distribution and range, communities and aquatic biodiversity; as well as increases in the number and spread of invasive and pest species, and in waterborne and vector-borne diseases, and extinction of vulnerable species (Dallas and Rivers-Moore, 2014).

\footnotetext{
* To whom all correspondence should be addressed:

๔ +27 0217801644; e-mail: helen@frcsa.org.za

Received: 27 November 2014; accepted in revised form 8 October 2015
}

Determining thermal limits experimentally is important for assisting with setting defendable, biologically-relevant water temperature guidelines for lotic systems. An approach adopted by Rivers-Moore et al. (2013a) for the ecological Reserve in South Africa is based on the 7-day moving average of mean, minimum and maximum daily temperatures, and exceedances. This is linked to a threshold temperature that signals when adverse biological responses are likely to occur. These threshold temperatures, which may reflect lethal or sublethal endpoints, are determined via laboratory or field studies. Lethal endpoints are commonly estimated using the Critical Thermal Method or the Incipient Lethal Temperature method (Dallas and Ketley, 2011; Dallas and Rivers-Moore, 2012; Dallas et al., 2015). Sublethal effects (i.e. non-lethal but which usually forces adaptation for survival) are numerous and, because they are often cumulative, may be reflected as a subtle process of attrition on populations and communities, through their differential effects on individuals of different species (Table 1). Effects include those altering an organism's physiology and metabolism (e.g. growth rates, secondary productivity, respiration), phenology (e.g. development time, voltinism, emergence), reproductive success and fitness (e.g. fecundity, rates and success of egg development and hatching), behaviour (e.g. migration, movement, drift), and broad-scale ecological effects (e.g. species richness, composition, densities and distribution patterns). Because the structure of living organisms is organised in a hierarchical manner, sublethal effects impacting on an individual organism or species may manifest at one or more levels in the hierarchy, namely populations, communities and entire ecosystems. Many studies on sublethal effects are carried out under natural conditions in the field, through regular sampling of sites over the period of at least 1 or 2 years (e.g. most phenological and ecological studies, Jacobsen et al., 1997; Verberk et al., 2008; 


\begin{tabular}{|c|c|c|c|}
\hline \multicolumn{4}{|c|}{$\begin{array}{c}\text { TABLE } 1 \\
\text { Summary of the major effects of sublethal water temperatures on aquatic organisms }\end{array}$} \\
\hline Major effects & $\begin{array}{l}\text { Response } \\
\text { variables }\end{array}$ & $\begin{array}{l}\text { General findings summarised from studies of } \\
\text { response variables in relation to temperature }\end{array}$ & Selection of relevant literature \\
\hline \multirow[t]{5}{*}{$\begin{array}{l}\text { Physiological and } \\
\text { metabolic }\end{array}$} & $\begin{array}{l}\text { Performance } \\
\text { curves }\end{array}$ & $\begin{array}{l}\text { Performance is optimal at intermediate temperatures } \\
\text { and outside of this range it is reduced. }\end{array}$ & \multirow{5}{*}{$\begin{array}{l}\text { Nebeker, 1971a; Heiman and Knight, 1975; } \\
\text { Brittain, 1976; Sweeney and Vannote, } \\
\text { 1978; Huey and Stevenson, 1979; Vannote } \\
\text { and Sweeney, 1980; Humpesch, 1981; } \\
\text { Brittain, 1983; Benke et al., 1984; Rigler and } \\
\text { Downing, 1984; Sweeney, 1984; Stearns, } \\
\text { 1989; Rowe and Ludwig, 1991; Giberson } \\
\text { and Rosenberg, 1992; Golubkov et al., } \\
\text { 1992; Atkinson et al., 1994; Atkinson, 1995; } \\
\text { Abrams et al., 1996; Angilletta et al., 2004; } \\
\text { Connolly et al., 2004; Manush et al., 2004; } \\
\text { Das et al., 2005; Reynolds and Benke, 2005; } \\
\text { Rostgaard and Jacobsen, 2005; Acuña et al., } \\
\text { 2008; Dallas and Ketley, 2011; Dallas and } \\
\text { Rivers-Moore, 2012; Rotvit and Jacobsen, } \\
\text { 2013; Verberk and Bilton, 2013; Verberk et } \\
\text { al., 2013. }\end{array}$} \\
\hline & Growth rates & $\begin{array}{l}\text { Growth rates increase with increasing temperature } \\
\text { to an optimum, after which they begin to decline } \\
\text { and tend to zero as thermal tolerance limits are } \\
\text { approached. Temperatures for optimal growth do } \\
\text { not translate to temperatures for optimal growth } \\
\text { efficiency, emergence success or length of emergence } \\
\text { period. }\end{array}$ & \\
\hline & Size at emergence & $\begin{array}{l}\text { Faster growth at warmer temperatures results in } \\
\text { smaller size at maturity. Colder temperatures result } \\
\text { in slower growth, longer development time and larger } \\
\text { size at maturity. }\end{array}$ & \\
\hline & $\begin{array}{l}\text { Secondary } \\
\text { productivity and } \\
\text { assimilation }\end{array}$ & $\begin{array}{l}\text { Secondary productivity is increased at warmer } \\
\text { temperatures. }\end{array}$ & \\
\hline & Respiration & $\begin{array}{l}\text { Respiration is increased at warmer temperatures } \\
\text { and oxygen may become a limiting factor at warmer } \\
\text { temperatures. }\end{array}$ & \\
\hline \multirow[t]{3}{*}{ Phenological } & $\begin{array}{l}\text { Total develop- } \\
\text { ment time }\end{array}$ & $\begin{array}{l}\text { Faster growth rates at warmer temperatures leads to } \\
\text { shorter development periods and may result in early } \\
\text { emergence cues in aquatic insects. }\end{array}$ & \multirow{3}{*}{$\begin{array}{l}\text { Nebeker, 1971a; Southwood, 1977; Clifford, } \\
\text { 1982; Brittain, 1982; Sweeney, 1984; } \\
\text { Sweeney et al., 1986; Perry et al., 1987; } \\
\text { Söderström, 1988; Southwood, 1988; Rader } \\
\text { and Ward, 1989; Brittain, 1990; Giberson } \\
\text { and Rosenberg, 1992; Sweeney et al., 1995; } \\
\text { Harper and Peckarsky, 2006; Verberk et al., } \\
\text { 2008; Elliott, 2009; Resh and Rosenberg, } \\
\text { 2010; Ross-Gillespie, } 2014 .\end{array}$} \\
\hline & $\begin{array}{l}\text { Voltinism } \\
\text { flexibility }\end{array}$ & $\begin{array}{l}\text { Warmer temperatures with greater variability promote } \\
\text { more generations produced in a year (bi- tri- or multi- } \\
\text { voltinism) and more flexible life histories; while more } \\
\text { conservative; less flexible life histories are selected for } \\
\text { under colder more stable conditions. Cold tempera- } \\
\text { tures result in slower growth rates; longer development } \\
\text { periods and delayed emergences in insects and are } \\
\text { normally associated with fewer generations over year } \\
\text { (univoltine life cycles). }\end{array}$ & \\
\hline & $\begin{array}{l}\text { Timing and } \\
\text { length of } \\
\text { emergence }\end{array}$ & $\begin{array}{l}\text { Extended; unsynchronised emergence periods in } \\
\text { aquatic insects at warm temperatures; more synchro- } \\
\text { nous and shorter emergence at cold temperatures }\end{array}$ & \\
\hline \multirow[t]{3}{*}{$\begin{array}{l}\text { Reproductive suc- } \\
\text { cess and fitness }\end{array}$} & Fecundity & $\begin{array}{l}\text { Fecundity is directly related to body size of females at } \\
\text { maturity and so declines with higher temperatures. }\end{array}$ & \multirow{3}{*}{$\begin{array}{l}\text { Green, 1966; Harper and Hynes, 1970; } \\
\text { Stearns, 1976; Humpesch, 1978, 1980; } \\
\text { Humpesch and Elliott, 1980; Sweeney } \\
\text { and Vannote, 1981; Sutcliffe and Carrick, } \\
\text { 1981; Humpesch, 1984; Brittain et al., } \\
\text { 1984; Tómasson et al., 1984; Elliott, 1984; } \\
\text { Brittain and Lillehammer, 1987; Elliott, } \\
\text { 1988; Lillehammer et al., 1989; Brittain, } \\
\text { 1991; Brittain and Campbell, 1991; Jackson } \\
\text { and Sweeney, 1995; Brittain, 1995; Sweeney } \\
\text { et al., 1995; Pritchard et al., 1996; Corkum } \\
\text { et al., 1997; Gillooly and Dodson, 2000; } \\
\text { Yoshimura et al., 2006; Knispel et al., 2006; } \\
\text { Ross-Gillespie, 2014. }\end{array}$} \\
\hline & $\begin{array}{l}\text { Rates and } \\
\text { success of egg } \\
\text { development }\end{array}$ & $\begin{array}{l}\text { Eggs develop faster with increasing temperatures that } \\
\text { are within egg development limits. Temperatures that } \\
\text { result in fastest egg development are not always those } \\
\text { that result in highest hatching success. Hatching suc- } \\
\text { cess is usually highest at temperatures slightly lower } \\
\text { than those that promote fastest development. High } \\
\text { temperatures approaching development limits lead to } \\
\text { deformed or retarded development and lower hatch } \\
\text { success. }\end{array}$ & \\
\hline & $\begin{array}{l}\text { Juvenile survival } \\
\text { and recruitment }\end{array}$ & $\begin{array}{l}\text { Low temperatures below species-specific thresholds } \\
\text { may induce egg diapause and similarly temperatures } \\
\text { above species-specific thresholds may terminate dia- } \\
\text { pause. Increased temperatures result in higher juvenile } \\
\text { mortality rates. }\end{array}$ & \\
\hline \multirow[t]{2}{*}{ Behavioural } & Migration & $\begin{array}{l}\text { Organisms migrate or move to a zone of thermal pref- } \\
\text { erence when introduced to a wide range of tempera- } \\
\text { tures; even if this means foregoing access to resources } \\
\text { such as food. }\end{array}$ & \multirow{2}{*}{$\begin{array}{l}\text { Hutchison and Manness, 1979; Gerritsen, } \\
\text { 1982; Baker and Feltmate, 1989; Richardson } \\
\text { et al., 1994; Hernández-Rodríguez and } \\
\text { Bückle-Ramirez, 1997; Bury et al., 2000; } \\
\text { Burks et al., 2002; Hernández-Rodríguez } \\
\text { et al., 2002; Gerald and Spezzano, 2005; } \\
\text { Rossetti and Cabanac, 2006; Tate et al., } \\
\text { 2006; McCullough et al., 2009. }\end{array}$} \\
\hline & Drift & $\begin{array}{l}\text { Dramatic and sudden increases in temperature } \\
\text { may lead to catastrophic drift in aquatic insects to } \\
\text { escape. Gradually increased temperatures may lead to } \\
\text { increased amplitude of diel drift. }\end{array}$ & \\
\hline
\end{tabular}


TABLE 1 (continued)

\begin{tabular}{|c|c|c|c|}
\hline Major effects & $\begin{array}{l}\text { Response } \\
\text { variables }\end{array}$ & $\begin{array}{l}\text { General findings summarised from studies of } \\
\text { response variables in relation to temperature }\end{array}$ & Selection of relevant literature \\
\hline \multirow[t]{4}{*}{ Ecological } & Species richness & $\begin{array}{l}\text { Richness generally increases with increased annual } \\
\text { water temperature variation. Increased variation in } \\
\text { diurnal temperatures favours certain species while } \\
\text { negatively affecting others. }\end{array}$ & \multirow{4}{*}{$\begin{array}{l}\text { Cummins, 1974; McMahon, 1975; Sweeney } \\
\text { and Vannote, 1978; Vannote et al., 1980; } \\
\text { Vannote and Sweeney, 1980; Ward and } \\
\text { Stanford, 1983; Hawkins, 1986; Townsend, } \\
\text { 1989; Brittain, 1991; Hart and Rayner, } \\
\text { 1994; Brittain and Bildeng, 1995; Hogg and } \\
\text { Williams, 1996; Williams, 1996; Vinson } \\
\text { and Hawkins, 1998; Gasith and Resh, 1999; } \\
\text { Jackson et al., 2001; Durance and Ormerod, } \\
\text { 2007; Ficke et al., 2007; Fjellheim and } \\
\text { Raddum, 2008; Gustafson, 2008; Rahel and } \\
\text { Olden, 2008; Woodward et al., 2010; Statzner } \\
\text { and Dolédec, 2011; Sheldon, 2012; Filipe et } \\
\text { al., 2013; Eady et al., 2013. Rivers-Moore et } \\
\text { al., 2013b. }\end{array}$} \\
\hline & $\begin{array}{l}\text { Species } \\
\text { composition }\end{array}$ & $\begin{array}{l}\text { Species composition is generally more diverse in habi- } \\
\text { tats experiencing a wider range of annual and diurnal } \\
\text { temperatures. }\end{array}$ & \\
\hline & Density & $\begin{array}{l}\text { Latitudes and altitudes promoting optimum tempera- } \\
\text { ture ranges for a wider range of species result in great- } \\
\text { est densities and abundances of those species. }\end{array}$ & \\
\hline & $\begin{array}{l}\text { Distribution } \\
\text { patterns }\end{array}$ & $\begin{array}{l}\text { Water temperatures control aquatic species distribu- } \\
\text { tion patterns. Cool headwaters represent ancestral } \\
\text { habitat of many aquatic insects. Colonisation of } \\
\text { lower reaches and lentic waters involved adaptation } \\
\text { to warmer thermal conditions. Cool waters represent } \\
\text { thermal refugia for cold adapted stenotherms. While } \\
\text { warm stenotherms and eurytherms are able to colonise } \\
\text { habitats exhibiting a wide range of temperatures. }\end{array}$ & \\
\hline
\end{tabular}

Ross-Gillespie, 2014). However, several questions related to the sublethal effects of temperature lend themselves more to experimental procedures undertaken in the laboratory over shorter time periods (e.g. studies on physiology, metabolism, reproductive success and behaviour, Brittain, 1976; 1991; Dallas and Ketley, 2011; Dallas and Rivers-Moore, 2012).

This paper provides an overview of the effect of sublethal temperatures on aquatic organisms, with discussion drawn from freshwater studies, in particular those focused on aquatic insects. Commonly-used methods, which vary from simple, cost-effective, laboratory-based methods to more elaborate, expensive, laboratory- and field-based studies, are assimilated to serve as a toolbox for future thermal research.

\section{Physiological and metabolic effects}

Studies relating to physiological and metabolic processes are commonly carried out in the laboratory (Brittain, 1976; 1991; Dallas and Ketley, 2011; Dallas and Rivers-Moore, 2012). Organisms are typically maintained under a range of constant temperatures or in digitally controlled water baths where temperature may be increased gradually and precisely. Body temperature is the most important ecophysiological variable affecting the performance of ectotherms and many physiologi$\mathrm{cal}$ and metabolic responses are sensitive to body temperature, including, for example, locomotion, foraging ability, rates of feeding and growth (Angiletta et al., 2002; Angiletta, 2006). Performance curves are often used to reflect the relationship between body temperature and a specific type of performance such as growth rate, and are described by an asymmetric function where maximum performance is achieved at intermediate body temperatures, termed the thermal optimum (Angiletta et al., 2002) (Fig. 1).

\section{Growth and size}

Growth rates of aquatic organisms are a function of ingestion, assimilation, activity and metabolism. Numerous studies have examined the relationship between development time and body size (Stearns and Koella, 1986; Roff, 1992; Berrigan and Koella, 1994; Atkinson, 1995; Nylin and Gotthard, 1998; Angiletta et

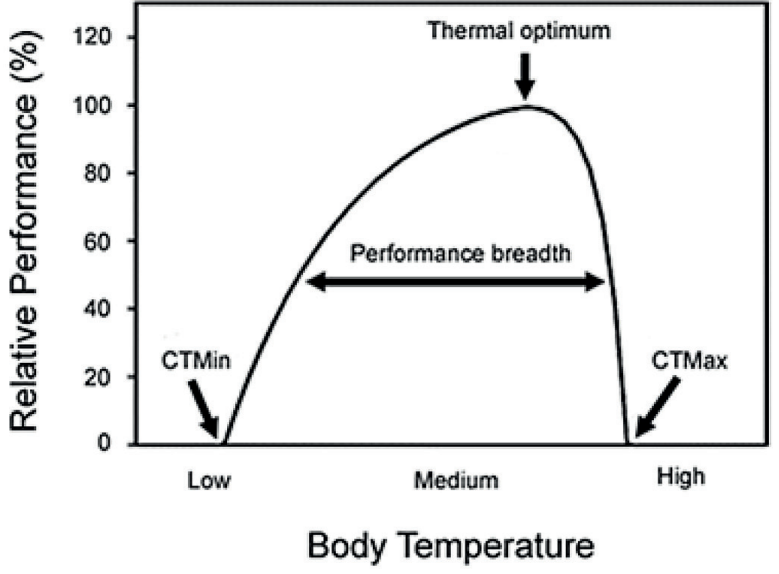

Figure 1

Representation of a typical performance curve for an aquatic organism where a specific performance measure is monitored at regular intervals as temperature is increased resulting in increased body temperatures. (Adapted from Angilletta et al., 2002)

al., 2004) and, generally, lower water temperatures result in decreased growth rates while warmer water temperatures cause an increase in growth rates, shorter development times and smaller adult size at emergence (e.g. Hynes, 1970; De Moor, 1982; 1994; Brittain, 1982; Ward and Stanford, 1982; Sweeney and Vannote, 1984; Giberson and Rosenberg, 1992; Sibly and Atkinson, 1994; Gillooly et al., 2002; Reynolds and Benke, 2005).

Growth is assessed by monitoring individual organisms over the entire growth period from hatching to adult emergence or over a particular part of the life cycle. At the start of the study period a subsample of study organisms are collected, measured (e.g. body length head capsule width), dried and weighed to obtain a length: mass relationship, which is typically exponential. Thereafter organisms are sampled at each interval and a small subsample is similarly measured, dried and weighed to provide length-to-biomass relationships for the full 
range of sizes over the study period. For the remaining organisms, sclerotised body parts are measured in conjunction with body length to provide a measure of increasing size. Where body length-to-biomass equations have been calculated for the study organism across a range of sizes, instantaneous growth rates are then calculated by determining the change in initial biomass compared to final biomass from hatching to emergence (Benke et al., 1984) or over the specific time period measured. Instantaneous growth rates as well as rates of body size increase may then be compared across temperature treatments to determine thermal optima for growth.

Similarly, growth rates may be calculated in relation to sex and age to determine if differences in growth exist as a result of the effects of sexual dimorphism or if growth rates vary over different developmental stages (e.g. Nylin and Gotthard, 1998; Shama and Robinson, 2006). In most aquatic organisms (especially aquatic insects) monitored in the laboratory, the number of flagellar segments on the antennae of organisms may be counted upon each successive moult and may be quantitatively related to body size and instars to provide an accurate measure of age (e.g. Khoo, 1964; Pöckl, 1992). Age may then be related to growth rate to determine if growth rate remains constant throughout the entire life cycle or if it changes at different stages.

\section{Secondary productivity}

Energy sources, primary and secondary productivity, producer communities and the ratio of production to respiration vary longitudinally down a river system (Vannote et al. 1980). Secondary productivity of a heterotrophic population, defined as the biomass accumulated by that population per unit time (Rigler and Downing, 1984; Benke and Huryn, 2006), is a function of assimilation efficiency and net production efficiency. Annual secondary productivity is the sum of all biomass produced by a population during 1 year, including production remaining at the end of the year and all production lost during this period (possibly through mortality, loss of tissue reserves through moulting and also emigration)(Benke and Huryn, 2006). Such information may be used to address (i) the transfer of energy or materials within communities and ecosystems, (ii) the rational management of aquatic resources, (iii) the detection of the effects of pollution and (iv) the formation of general theories of biological productivity (Downing, 1984)

Secondary productivity has been shown to increase in relation to increasing water temperature (where these temperatures are within the thermal tolerance limits of the organism) in conjunction with increases in biomass levels. As high growth rates and high biomass are not commonly maximised in conjunction with each other, it is often the case that rapid growth rates are concomitant with low biomass, while slow to moderate growth rates are more commonly associated with high biomass (Huryn and Wallace, 2000). Warm temperate streams, subject to frequent physical disturbance from high flow events, tend to yield higher levels of production as these conditions select for taxa with rapid growth rates, short development periods and smaller sizes at maturity (Huryn and Wallace, 2000). In such scenarios production is driven by rapid growth rates rather than biomass accrual (Huryn and Wallace, 2000). While water temperature plays a major role in driving secondary production, photoperiod as well as nutrition quantity and quality are additional factors that should be considered when assessing optimum rates of secondary productivity (Savage, 1986; Sweeney and Vannote, 1981; Giberson and Rosenberg, 1992; Reynolds and Benke, 2005).
While several methods exist for calculating secondary productivity (Waters and Crawford, 1973; Rigler and Downing, 1984; Benke and Huryn, 2006) certain common data, namely measures of mean body mass of individuals as well as an estimate of the number of individuals (density) for each time period or size class (Rigler and Downing, 1984), are required. These data are attained by taking samples of the population at different times during its development, or by splitting the population over the entire growth period into different size classes (Rigler and Downing, 1984). The history of the population or cohort is then reconstructed as a simplified histogram of numbers of individuals against individual mass (Rigler and Downing, 1984). Calculations of secondary productivity are usually accomplished with field studies, although laboratory experiments may be used to obtain insight into selected aspects of production processes for a specific time period under different environmental conditions (Gulati, 1974; Lutterschmidt and Hutchinson, 1997).

\section{Respiration}

At warmer temperatures growth rates are faster, as are metabolic demands for oxygen (Hutchison, 1981; Verberk et al., 2011). The solubility of oxygen in water is inversely related to temperature (Dallas and Day, 2004) and oxygen shortages arise as water temperature increases. The result is that cardiac and ventilatory activities of aquatic organisms may become unable to provide sufficient oxygen at high temperatures, which subsequently leads to a shift from aerobic to anaerobic metabolism to conserve energy status (Frederich and Pörtner, 2000; Verberk et al., 2013). Furthermore, in nutrient-rich systems the high respiration activity of algae or macrophytes at night depletes available oxygen resources, especially at warmer temperatures. Respiration rates may be measured at a range of water temperatures to determine at which threshold temperatures oxygen becomes a limiting factor. More specifically the temperature that triggers the onset of anaerobic metabolism (Verberk et al., 2013), or is observed to be detrimental to a performance response (e.g. locomotion, foraging), may be determined experimentally using respiration chambers. Over the past 3 decades, with the introduction of respirometer chambers by McIntire et al. (1964), scientists have been able to successfully determine respiration rates of individual organisms and benthic communities in the laboratory (Bott, 2006). These chambers allow for control of environmental factors such as water temperature, which is then related to metabolic parameters or performance responses (Bott, 2006).

\section{Phenological effects}

Phenological effects are those related to total developmental period, voltinism (i.e. the number of annual broods, generations or cohorts produced by an organism in a year), type of life cycle and the timing of specific life-history events such as hatching or emergence (Hynes, 1970; Verberk et al., 2008). Life-history studies, autecology and descriptive ecology provide fundamental information necessary to conduct virtually all modern evolutionary and applied ecological studies, particularly those relating to aquatic invertebrates (Butler, 1984; Verberk et al., 2008; Resh and Rosenberg, 2010). Understanding an organism's life-history allows one to predict the response of that organism to variation and change in environmental parameters such as temperature (Power et al., 1988; Resh and Rosenberg, 2010). 


\section{Total development time and voltinism}

Since temperature exerts a major control over metabolic processes and growth, organisms with faster growth rates may complete their development in a shorter period and thus produce more generations or cohorts in a single year compared to those with slower growth rates. Voltinism ranges from univoltine (1) to bivoltine (2), trivoltine (3) and polyvoltine (3 or more) generations within a year. Semi-voltine organisms are those in which a single generation may take 2 or 3 years to develop (Hynes, 1970; Clifford, 1982). Some species of aquatic insect (e.g. the univoltine Palearctic Leptophlebia species and Nearctic Leptophlebia cupida) exhibit fairly constant development times and voltinism over a wide range of latitudes, climates and environments (Clifford et al., 1979; Brittain, 1982). Others (e.g. multivoltine Baetidae, Simuliidae as well as the univoltine species Rhithrogena semicolorata) vary the number of generations produced in a year to suit local environmental conditions thereby exhibiting a large degree of flexibility in their life cycle development time and consequently their voltinism over their distributional range (Hynes, 1970; Humpesch, 1979; Ward and Stanford, 1982).

The majority of life-history studies are based on regular field observations or samples collected from one or more sites for a period of a year or longer. Organisms collected in each sample for each time period are enumerated to provide either relative abundance or density, measured (body length, head capsule width) and assigned either a life cycle stage or instar (e.g. using antennal counts). The number and size of organisms may then be tracked through time from hatching to adult emergence to provide insight into the number of generations produced in a year, the length of development period and the timing of adult emergence. Temperature has been shown to influence all of these phenological aspects (Ross-Gillespie, 2014). For example, the univoltine mayfly, Lestagella penicillata, had a slower development period (with a greater number of larval instars) and also later emergence in cold rivers compared to warm ones (Ross-Gillespie, 2014).

While comparatively few life-history studies have been conducted in the laboratory compared to the field, field studies may leave gaps in knowledge such as the length of the adult flight period, differential effects of sexual dimorphism, methods of oviposition, duration of egg development, presence of diapause and hatching success. Laboratory setups such as aerated containers, flow-through systems or field-based mesocosms are useful as they are able to mimic natural conditions in a contained and controlled environment (e.g. Humpesch, 1979; Sweeney and Vannote, 1981; Sweeney et al., 1986; Peckarsky and Cowan, 1991; Giberson and Rosenberg, 1992; Reynolds and Benke, 2005; Harper and Peckarsky, 2006; Kendrick and Benstead, 2013). In such setups the effect of certain environmental factors, that under natural conditions co-vary, may instead be decoupled, independently controlled and experimentally tested (e.g. photoperiod, temperature regime, flow rate, oxygen saturation). Generally, more modern systems now allow for either constant or fluctuating thermal regimes with a high level of precision and control over a number of variables (e.g. Clements et al., 2013). While these systems may never truly replicate natural conditions to the same degree of efficiency, they do allow for the complicated interaction of variables affecting the life histories of aquatic insects to be broken down and studied separately. For example, laboratory studies have been used to explore the effect of temperature on voltinism - especially using organisms that have naturally fast growth rates and short development times (e.g. Chironomidae: Reynolds and Benke, 2005).

\section{Timing and duration of emergence}

Emergence is the transition from the aquatic nymphal stage to the terrestrial sub-imago during which the nymphal skin is shed, normally at the water's surface or on surrounding riparian vegetation (Brittain, 1982). Emergence is influenced by variations in the growth rate of the pre-emergent nymphal population and is an integral component of life cycle strategies (Brittain, 1990). Irregular timing of emergence in species, owing to altered thermal regimes in rivers, may be lethal to aquatic insects, because (i) they may emerge in conditions potentially unsuitable for their survival (i.e. asynchronous emergence with resources such as food/prey) (Nebeker, 1971a; Raddum, 1985) and (ii) males might emerge and die before females emerge, preventing successful mating (Nebeker, 1971a). As such, many aquatic insects are adapted so that seasonal changes in temperature act as cues for the timing of emergence. The timing and duration of emergence involves responses mainly to water temperature, often interacting with combinations of photoperiod, dissolved oxygen and flow (Nebeker, 1971a; Ward and Stanford, 1982).

The sublethal effects of temperature on the timing and duration of emergence are particularly well suited to laboratory studies. Immature nymphs of aquatic insects may easily be collected from the field, acclimated and then transferred to aerated containers, flow-through systems or field-based mesocosms, in which they may be reared to maturity under different experimental conditions. Water temperatures may be manipulated using either static or fluctuating thermal regimes to determine the effect of temperature on the timing and duration of emergence. Laboratory studies of this sort have been able to demonstrate that (i) specific threshold temperatures may initiate emergence, (ii) emergence may be hastened or delayed by adjusting experimental water temperatures, (iii) emergence period is extended in warmer conditions, (iv) larger size and higher fecundity at emergence is caused by cooler temperatures, (v) adult longevity is increased when nymphs are reared at cooler temperatures, and (vi) the time between emergence of males and females is increased with increasing temperature (Nebeker, 1971a, b; Brittain, 1976; Sweeney, 1978; Sweeney and Vannote, 1981; Ward and Stanford, 1982; Giberson and Rosenberg, 1992; Harper and Peckarsky, 2006).

Field studies have also been undertaken to investigate timing and duration of emergence as well as total development time and voltinism (Ross-Gillespie, 2014). By selecting rivers that naturally vary with respect to water temperature and flow, RossGillespie (2014) showed that all of these life history attributes are influenced by thermal and hydrological regimes. Data collected from emergence traps in field studies and from laboratory studies of mayflies have revealed both diel (largely crepuscular) and seasonal patterns (occurring mostly during the warmer months) of emergence, as well as latitudinal and altitudinal differences resulting in the shifting of the timing of emergence (onset of emergence delayed with increasing altitude and higher latitudes, most likely associated with cooler water temperatures) (Brittain, 1982; Ward and Stanford, 1982; Campbell, 1986). Where several species co-exist (e.g. congeneric species), peak emergences are separated in time, with either synchronised or dispersed patterns exhibited (Brittain, 1982; Ward and Stanford, 1982).

\section{Effects on reproductive success and fitness}

\section{Fecundity}

Adult female body size of aquatic insects has been found to be directly related to fecundity, with females of larger species 
producing more eggs (Brittain, 1982; Ward and Stanford, 1982). As water temperature has been shown to affect growth rates of nymphs and final body size at emergence, the trade-off between growth and sexual development under environmental time constraints has evolutionary and ecological implications on fecundity (Ward and Stanford, 1982). Numerous laboratory studies have investigated the sublethal effects of water temperature on the fecundity of reared female aquatic insect nymphs in conjunction with the size or fitness of reared adults at emergence (e.g. Sweeney and Vannote, 1981; Giberson and Rosenberg, 1992; Elliott, 2013). For these experiments the general approach is to collect immature nymphs from the field and rear them to maturity in systems similar to those used to obtain information on growth rates, life cycle development times as well as voltinism. As spermatogenesis and oogenesis are completed in the final nymphal instar of most aquatic insects (Britain, 1982), upon emergence, females are collected, their body size measurements recorded, after which they are dissected in order to count the number of eggs produced.

\section{Rates and success of egg development and hatching}

Water temperature is the principal factor determining the rate of development of eggs, hatching success, the length of the hatch period, as well as the induction and termination of egg diapause in aquatic insects (Brittain, 1982; Ward and Stanford, 1982; Gillooly and Dodson, 2000). It has been suggested that specific threshold or critical temperatures determine the onset and breaking of egg diapause (i.e. an egg resting stage during which no development occurs - a mechanism for evading unfavourable or stressful conditions) in certain aquatic insect species and in some cases hatching success as well as the length of the egg incubation period (Elliott, 1972; Humpesch, 1980; Lillehammer et al., 1989). Critical thermal limits for egg development provide an indication of the range of temperatures suitable for the growth of juvenile nymphs, which is useful for determining the effects of water temperature on recruitment.

As aquatic insect eggs do not require nutrition for development (Pritchard et al., 1996), generally have low oxygen requirements, and are unaffected by photoperiod or flow velocities (Brittain, 1982), they are ideal subjects for simple, cost-effective laboratory experiments. Eggs to be used in these experiments are usually collected from mated, gravid adult organisms captured in the field by means of a hand net or aspirator. By submerging containers in pools used as oviposition sites, eggs may also be directly collected from the field, where mated females might be difficult to obtain. Gravid females of some mayfly and stonefly species, when captured and placed in vials or jars containing some water, freely oviposit eggs, while many caddisfly adults readily mate and oviposit under laboratory conditions (Brittain and Lillehammer, 1987; Elliott, 1988; Ross-Gillespie, 2014), providing a simple means of obtaining eggs. Where these approaches are not possible or prove to be unsuccessful, eggs may be obtained through artificial fertilisation techniques, which have proved successful for many species of mayfly that do not readily mate in the laboratory (Humpesch, 1980; Brittain, 1982; Sweeney and Vannote, 1987; Ross-Gillespie, 2014). Once eggs have been collected they may be placed in water-filled containers (e.g. petri dishes, beakers or tanks) and held at either constant or fluctuating temperature regimes. Eggs are monitored daily for signs of development, diapause and hatching. Upon hatching the number of successfully hatched eggs at each temperature is recorded along with the length of the hatch period and ultimately the egg development period (normally the length of time measured as degree days to median hatch) is calculated (Pritchard et al., 1996). Degree days, i.e., the cumulative temperature experienced by an organism above a certain threshold temperature for development, allow one to calculate, for example, the probability of egg hatching under different thermal conditions (Rivers-Moore et al., 2013b).

Experiments of this sort have generated a large amount of literature and have provided valuable insights into the ecological and evolutionary strategies adopted by a range of aquatic organisms to deal with different thermal environments, including aquatic insects (Brittain, 1976; Humpesch, 1980; Brittain, 1982; Elliott, 1984, 1988, 2009; Sweeney and Vannote, 1984; Brittain and Lillehammer, 1987; Jackson and Sweeney, 1995; Pritchard et al., 1996; Reynolds and Benke, 2005; Elliott, 2013; Ross-Gillespie, 2014), amphipods (Sutcliffe and Carrick, 1981; Pöckl and Timischl, 1990) and fish (Brungs, 1971; Fonds, 1979; Mitchell, 1989; Crisp, 1990; Semmens and Swearer, 2011). Some common trends observed in these studies, particularly those focused on aquatic insects, have been that lower water temperatures generally result in longer egg development times, while shorter development times are observed at warmer temperatures and also under fluctuating or diel thermal regimes when compared to constant temperatures (Humpesch, 1978; Ward and Stanford, 1982). As such, the relationship between temperature and time to hatch in many species of Ephemeroptera and Plecoptera may be described by the power law (Brittain, 1982; Lillehammer et al., 1989). When thermal conditions are at an optimum the hatching period of eggs is generally short; however highly variable hatch durations have been observed both within and among species (Ward and Stanford, 1982). Extended hatch durations have also been observed in laboratory conditions (Clifford et al., 1979) and at higher temperatures in conjunction with lower hatch success (Ross-Gillespie, 2014), which may suggest that extended hatches are an adaptive response to unpredictable conditions (Ward and Stanford, 1982). Interestingly, hatching success is also not necessarily highest at temperatures which permit the fastest development of eggs (Ward and Stanford, 1982, RossGillespie, 2014). Information on thermal limits for egg development in aquatic organisms is still limited and originates largely from northern Hemisphere studies on aquatic insects, namely the Ephemeroptera, Plecoptera and Trichoptera (Britain, 1982), with few examples from the southern Hemisphere (e.g. Brittain, 1991, 1995; Dallas and Rivers-Moore, 2012, Ross-Gillespie, 2014). Egg diapause (i.e. a period of suspended activity broken by an appropriate environmental cue) has been observed over both summer and winter periods for several species of aquatic insect (Ephemeroptera, Plecoptera, Simulidae: Harper and Hynes, 1970; Hynes, 1970; Brittain, 1975; Pritchard et al., 1996) and Crustaceans (Cladocera: Frey, 1982; Yurista, 1997; Slusarczyk and Rybicka, 2011).

\section{Behavioural effects}

Behavioural responses that allow ectotherms to exploit the thermal heterogeneity of their environments, in order to maximise biochemical and physiological processes or enhance survivability, thereby indirectly influencing reproductive and ecological efficiency, are termed thermoregulatory behavioural responses (Hutchison and Maness, 1979; Gerritsen, 1982; Hutchison and Spriestersbach, 1986). Mechanisms that control 
behavioural thermoregulation in ectotherms are more sensitive to temperature change than mechanisms controlling physiological adjustments (Cabanac, 1979). Studies on thermoregulatory behaviour have primarily been undertaken on fish and reptiles with comparatively fewer studies conducted on amphibians and aquatic invertebrates (Hutchison and Spriestersbach, 1986; Dallas, 2008). Locomotion, through migration and drift, is commonly associated with thermoregulatory behaviour in aquatic ectotherms because in the aquatic environment most organisms have to move significantly further in order to accomplish a change in body temperature compared to terrestrial organisms (e.g. lizards), which are better able to control rates of heat gain or loss through changes in posture or orientation (Hutchison and Spriestersbach, 1986).

Aquatic organisms, particularly fish, are known to utilise thermal refugia and often thermoregulate by migrating to areas of cooler water when surrounding water temperatures are outside of their preferred range or exceed their upper tolerances (e.g. Torgersen et al., 1999; Elliott, 2000; Ebersole et al., 2001; Gardner et al., 2003). Fish possess acute temperature discrimination powers and use behaviour to avoid or rapidly escape thermally hostile areas, if thermally favourable environments are available (Beitinger et al., 2000). The habitat occupied by a particular species or age class, in the field, has been shown to change seasonally and even daily in response to the location of preferred temperatures (Coutant, 1987). Thermal refugia protect biotic communities from extreme thermal disturbances and are most numerous in intact riverine systems with riparian vegetation and groundwater (Torgersen et al., 1999). Undercut banks and overhanging vegetation also increase the availability of less thermally stressful habitats (Bell, 2006). Coldwater patches, which may be $3^{\circ} \mathrm{C}$ to $10^{\circ} \mathrm{C}$ lower than instream temperatures, are normally associated with lateral seeps, cold sidechannels, floodplain tail seeps, floodplain seeps and stratified pools (Mosley, 1983; Ebersole et al., 2001).

For many aquatic insects the hyporheic habitat (particularly coarse substrate, such as cobbles) provides a refuge from fast velocities (boundary layer effect), low temperatures (geothermal groundwater inputs, buffered water temperatures, protection from underwater ice) and also high temperatures (from cooler groundwater exchanges, lack of incoming solar radiation) temperature extremes (Hynes, 1970; Brown et al., 2005; Caissie, 2006). When compared to surface water temperatures, intragravel temperatures within the substratum have been found to be lower during summer and higher over winter (Caissie and Giberson, 2003; Brown et al., 2005). As a result many aquatic insects may simply migrate down into the substrate a relatively short distance to gain shelter from adverse conditions (Hynes, 1970). Similarly, the temperature differential in the substratum may influence fish habitat conditions (Crisp, 1990) and the development of salmonid eggs (Combs, 1965; Alderdice and Velsen, 1978; Beer and Anderson, 2001). Aquatic crustacean zooplankton also exhibit thermoregulatory behaviour in the form of migration, where they swim upwards in response to sudden increases in temperature and sink in response to decreases in temperature (Barber, 1961; Gerritsen, 1982). Similar responses in zooplankton have been found as a result of diel, seasonal, and interannual changes as well as thermal stratification in lakes and dams (Gorski and Dodson, 1996; Ryan and Dodson, 1998; Burks et al., 2002; Beklioglu et al., 2008; Schalau et al., 2008; Ziarek et al., 2011). The frequency of upward swimming has been found to be proportional to the rate of change of temperature (Gerritsen, 1982). Phototactic responses may however complicate matters, where cool animals exhibit positive phototactic reactions and swim upwards towards a light source and warm organisms exhibit a negative phototactic reaction swimming away from a light source (Gerritsen, 1982). The amplitude of diel patterns of invertebrate drift may also be increased at warmer temperatures (Waters, 1972; Keller, 1975; Brittain and Eikeland, 1988), while catastrophic drift responses may result from drastic and sudden temperature changes (Ward and Stanford, 1982).

A popular method of investigating thermoregulatory behaviour in fish, crustaceans and aquatic insects in the laboratory is through the use of either vertical or horizontal thermal gradient tanks (Cherry and Cairns, 1982; Boubée et al., 1991; Richardson et al., 1994). This technique involves the establishment of a temperature gradient (either horizontal or vertical) that is then used to evaluate, by determining movement into different thermal zones and the time spent in these zones, the temperatures preferred or avoided by an organism. The method facilitates the determination of the effects of gradual temperature changes and allows ontogenetic shifts in temperature preferences to be calculated. For example, Boubée et al. (1991), using a thermal gradient tank, showed experimentally that the final preferred temperature of Galaxias maculates, a resident fish in New Zealand, is about $20^{\circ} \mathrm{C}$ and that temperatures above $29.5^{\circ} \mathrm{C}$ were totally avoided. These laboratory setups have been successfully used for adult Coleoptera (Ybarrondo, 1995), larval Odonata (Leggott and Pritchard, 1986; Baker and Feltmate, 1989), larval Tipulidae (Kavaliers, 1981), Palaemonidae (Hernández-Rodríguez and Bückle-Ramirez, 1997), Gastropoda (Kavaliers, 1980, Rossetti et al., 1989; Gerald and Spezzano, 2005), hatchling and yearly freshwater turtles (Bury et al., 2000) and fish (Boubée et al., 1991; HernándezRodríguez et al., 2002).

\section{Ecological effects}

Water temperatures may influence patterns of species richness, composition, densities and distribution of aquatic organisms, both within and among aquatic habitats (Coutant, 1977; Brittain, 1982; Ward and Stanford, 1982; Downes et al., 1993; Wichert and Lin, 1996; Jacobsen et al., 1997; Dallas and RiversMoore, 2012; Rivers-Moore et al., 2013b). Temperature is the abiotic variable most closely related to changes in latitude and altitude which have both, through several studies from tropical and temperate regions, been found to impact aquatic community structure and species diversity (Hynes, 1970; Kownacka and Kownacki, 1972; Stout and Vandermeer, 1975; Ormerod et al., 1994; Jacobsen et al., 1997; Jacobsen, 2004). Diversity and species richness have been found to increase with increasing water temperature and decrease with altitude and latitude (Brittain, 1982; Jacobsen et al., 1997). Estimates suggest that tropical lowland streams have on average two to fourfold higher species richness than temperate lowland streams (Jacobsen et al., 1997). Faster rates of evolution and speciation as a result of shorter generation times and elevated mutation rates at increased temperatures have been proposed by Rohde (1992) to explain the greater levels of diversity observed at warmer temperatures and thus further elucidate the potential causes for the latitudinal gradients observed in biodiversity. Several studies also illustrate a zonation pattern of aquatic organisms along the longitudinal profile of rivers concomitant with thermal differences along the profile (e.g. Brittain, 1975; Ward, 1985; Jacobsen et al., 2010). These studies, however, have been thought to obscure the actual effect of temperature (Jacobsen et al., 1997) because habitat type (which has a major 
effect on species composition, richness, and density) changes along the profile (Minshall, 1985; Jacobsen and Friberg, 1997; Voelz and McArthur, 2000).

Ward and Stanford (1982), citing several other authors, suggest that unpredictable thermal environments, particularly those which experience a wide annual temperature range, enhance species diversity in several ways: (i) such conditions are suitable for wide range of organisms (cold stenotherms, warm stenotherms as well as eurytherms), (ii) a greater number of species may co-exist especially when temporal segregation occurs as a result of differential thermal responses during different periods of the annual thermal cycle, (iii) species may avoid competition during different parts of the year through niche segregation as a result of the specific thermal limits for the induction and termination of dormancy that have evolved at both high and low temperature extremes and also temporal separation of resource use as well as emergence times, (iv) wide daily variation in temperature may provide a greater range of thermal optima and allow for increased species packing (see MacArthur, 1970 and Case, 1981), despite the fact that suboptimal conditions would be encountered by each species for a part of the diel cycle.

Investigations into the ecological effects of sublethal temperatures on aquatic organisms have generally been undertaken in field studies where the entire community is considered. This is largely because of the complexities involved in ensuring that artificial systems afford the same opportunities for colonisation, succession and diversity of aquatic organisms that is offered by natural systems along with similar stable chemical and physical properties (Warren and Davis, 1971). Some of the most insightful studies relating the effect of water temperature to aquatic species richness, composition, density and distribution have been those where (i) hypolimnetic flows are released from dams and reservoirs upstream (e.g. Raddum, 1985; Brittain and Saltveit, 1989; Brittain, 1991; Gooseff et al., 2005), (ii) heated effluents enter the channel (e.g. Langford and Aston, 1970; Langford, 1990), (iii) whole in-channel manipulations have been undertaken (e.g. Hogg and Williams, 1996), (iv) similar natural systems with differing thermal regimes have been contrasted (e.g. Minshall et al., 1985; Jacobsen et al., 1997; Castella et al., 2001; Haidekker and Hering, 2008; Friberg et al., 2009), and (v) long-term data sets have revealed evidence for effects of global climate change (e.g. Durance and Ormerod, 2007).

\section{Methods for estimating sublethal effects}

Numerous laboratory setups and experimental procedures have been used to measure sublethal effects of temperature on aquatic organisms. Choice of laboratory setup largely depends on the question(s) being asked and available resources, with some setups well suited for the investigation of several response variables, either simultaneously or in sequence (Table 1). For instance aerated containers and flow-through systems may be used to determine growth rates, size at emergence, total development time, voltinism, emergence patterns and fecundity, thus incorporating response variables from three major effect categories, viz., physiological/metabolic, phenological and

TABLE 2

Summary of experimental setups, time frame and equipment costing that may be used to determine sublethal effects of water temperature on aquatic organisms

\begin{tabular}{|c|c|c|c|c|}
\hline Major effects & Response variables & Laboratory setup & Time framet & Cost $\neq$ \\
\hline \multirow{4}{*}{$\begin{array}{l}\text { Physiological and } \\
\text { metabolic }\end{array}$} & Growth rates & AC, W, F, M & Medium-Long & Low-Medium \\
\hline & Size at emergence & $\mathrm{AC}, \mathrm{W}, \mathrm{F}, \mathrm{M}$ & Medium-Long & Low-Medium \\
\hline & Secondary productivity & $\mathrm{M}, \mathrm{A}, \mathrm{N}$ & Long & High $^{*}$ \\
\hline & Respiration & $\mathrm{R}$ & Short & Medium \\
\hline \multirow{3}{*}{ Phenological } & Total development time & $\mathrm{AC}, \mathrm{W}, \mathrm{F}, \mathrm{M}$ & Long & Low-Medium \\
\hline & Voltinism and flexibility & $\mathrm{AC}, \mathrm{W}, \mathrm{F}, \mathrm{M}$ & Long & Low-Medium \\
\hline & $\begin{array}{l}\text { Timing and duration of } \\
\text { emergence }\end{array}$ & $\mathrm{AC}, \mathrm{W}, \mathrm{F}, \mathrm{M}$ & Medium-Long & Low-Medium \\
\hline \multirow{3}{*}{$\begin{array}{l}\text { Reproductive success and } \\
\text { fitness }\end{array}$} & Fecundity & WC, AC, W, F & Medium & Low-Medium \\
\hline & $\begin{array}{l}\text { Juvenile survival and } \\
\text { recruitment }\end{array}$ & WC, AC, F & Medium & Low \\
\hline & $\begin{array}{l}\text { Rates of egg development } \\
\text { and hatch success }\end{array}$ & WC, W & Medium & Low \\
\hline \multirow{2}{*}{ Behavioural } & Migration & $\mathrm{T}$ & Short & Low-Medium \\
\hline & Drift & T, A, N & Short-Medium & Medium-High ${ }^{*}$ \\
\hline \multirow{4}{*}{ Ecological } & Species richness & $\mathrm{M}, \mathrm{A}, \mathrm{N}$ & Long & Low-High* \\
\hline & Species composition & $\mathrm{M}, \mathrm{A}, \mathrm{N}$ & Long & Low-High* \\
\hline & Density & $\mathrm{M}, \mathrm{A}, \mathrm{N}$ & Long & Low-High* \\
\hline & Distribution patterns & $\mathrm{M}, \mathrm{A}, \mathrm{N}$ & Long & Low-High* \\
\hline
\end{tabular}

WC: water-filled containers, AC: aerated containers, W: water bath, F: flow-through systems, R: respiration chambers, M: mesocosms, T: thermal gradient tank, A: artificial stream, $N$ : natural stream

${ }^{*}$ High cost only where mesocosms and artificial streams are used

†Times frames are roughly estimated as: short (hours; days); medium (days; weeks); long (months; years) - variable, dependent on organisms to be studied, acclimation time and desired duration

$\ddagger$ Cost ratings in US\$ (estimates) are: low (50-500); medium (500-1000); high (>1 000) - costs are estimated under the assumption that major laboratory infrastructure exists (e.g. constant environment rooms) 
reproductive success. The response variables from each major effect category, their associated experimental setup, experimental timeframe and a rough costing have been summarised in Table 2. Key aspects that encompass all laboratory setups include: (i) use of chemically inert substance for construction of experimental setup; (ii) use of stream water or dechlorinated mains water that has been circulated in a reservoir for approximately $24 \mathrm{~h}$; (iii) use of a constant environment (temperature control) room that has either a constant temperature or a fluctuating temperature set to reflect ambient temperature and full-spectrum lighting controlled through a time switch to allow for an adjustable or constant photoperiod; and (iv) supply of a standardised food source for longer duration experiments.

\section{Water-filled containers}

These are commonly used for assessing growth rates, development times and hatching success of aquatic insect eggs, and juvenile survival rates of newly-hatched organisms (e.g. Reynolds and Benke, 2005; Brittain, 1976). They are amongst the simplest and cheapest of laboratory setups and involve the use of containers of any shape or size that are filled with water. The water in the container is not required to be aerated, but a portion of water is replaced manually with fresh water on a daily basis. The lack of aeration limits the utility of these containers for experiments.

\section{Aerated containers}

This laboratory setup comprises a set of containers filled with water that is aerated, using pumps or compressed air via airstones, to maintain the oxygen concentration at saturation levels. Normally experiments include a control (at ambient stream temperature) and several containers that are heated using calibrated aquarium heaters to provide constant temperatures above the control. These systems are generally self-contained, and for longer duration experiments $(>10$ days) water needs to be manually replaced with fresh water to maintain stability and quality of water and prevent accumulation of nutrients. Filtration canisters may be used to assist in the maintenance of a stable environment. The use of aerated containers provides a simple, cost effective experimental setup for investigating a number of sublethal effects on individuals. They are most appropriate for experiments of $\leq 10$ days as accumulation of nutrients becomes a problem thereafter, even with replacement of water.

\section{Water baths}

Water baths (volumes range from $1.5 \ell$ to $43 \ell$ ) allow for thermostatically-controlled water temperature with a high degree of precision, often via a digital interface or computerbased program that enables full customisation of heating rates. Generally, baths have operating temperatures from ambient temperature to $95^{\circ} \mathrm{C}$, while more advanced baths also have cooling capabilities with built-in temperature logging capabilities. The interior of the baths is usually constructed from seamless sheets of stainless steel which are corrosion-resistant and chemically inert and thus do not affect aquatic organisms. Many newer baths control temperature uniformity by circulation of water using built-in pumps, which concurrently serve to aerate the water. Water baths allow for temperatures: (i) to be increased and decreased at constant rates, (ii) kept constant or (iii) programmed to fluctuate according to a user-defined profile. Water baths are more expensive than aerated containers, with greater precision attained when heating and cooling is undertaken. For stable thermal experiments, aerated containers with heaters provide a more cost-effective option.

\section{Flow-through systems}

These are relatively small channels, flumes or containers of varying sizes that receive controlled and constant in-flows of fresh water that is then circulated and aerated by motorised paddle wheels or pumps (e.g. Warren and Davis, 1971; Oldmeadow et al., 2010; Ditsche-Kuru et al., 2012). Flow rates in the system are precisely regulated to mimic natural stream velocities at constant rates. Overflow pipes or overshot weirs allow excess water to drain out of the system, thus maintaining water depth and velocity whilst also allowing for the removal of nutrients and ensuring water remains chemically stable. Additional aeration by means of compressed air via airstones may be used to ensure oxygen content remains close to saturation. Flow-through systems represent a more realistic river environment but are more complex and costly to setup.

\section{Respiration chambers}

Respiration chambers specially designed for aquatic organisms are widely available and come in a range of sizes (from $0.5 \mathrm{~m} \ell$ to $30 \mathrm{l}$ ) for measuring respiration in individual eggs, embryos, larvae and mature adult fish. Chambers are constructed from chemically inert materials that do not act as oxygen sinks and provide airtight seals (e.g. borosilicate glass, perspex). Chambers are designed to allow oxygen probes to be hermetically mounted or inserted inside the chamber to continuously log or allow for manual measurements of oxygen concentration at regular intervals (Golubkov et al., 1992). Respiration is recorded as other environmental factors are adjusted (normally temperature and or photoperiod). Simple systems have water circulated by means of a magnetic stirrer, where a false bottom or piece of nylon mesh protects the study organism from the stirrer and provides an attachment surface (Verberk et al., 2013). Some advanced designs allow for respiration to be measured in swimming fish, by creating a flow-through system using a pump which is built into the design (Jones et al., 2007; Kieffer and Cooke, 2009; Pettersson et al., 2010). Certain challenges exist with regard to the use of respiration chambers in the laboratory, however, such as mimicking natural flow conditions and velocities as well as hyporheic processes and exchanges, maintaining natural nutrient levels, and controlling for excess heat generated from pumps (Rostgaard and Jacobsen, 2005; Bott, 2006).

\section{Mesocosms}

Mesocosms are water-filled or aerated containers, flow-through systems or sets of either of these that are maintained outdoors under semi-natural conditions (Caquet et al., 2000). The term semi-natural is used because certain environmental variables may be controlled, while others cannot. For instance several mesocosms have comprised flow-through systems setup inside greenhouses where air/water temperature and humidity are controlled, but photoperiod remains natural (e.g. Harper and Peckarsky, 2006; Clements et al., 2013). Mesocosms generally tend to be on a larger scale (Harper and Peckarsky, 2006; Wesner, 2010; Greig et al., 2012) than other systems housed in 
laboratories; however, they may be used for the same experimental investigations (e.g. growth, development times, emergence timing and length of life cycle, voltinism flexibility). Mesocosms utilise ambient conditions, with costs dependent on experimental setup. A secure experimental location is critical for the success of this option.

\section{Thermal gradient tanks}

Thermal gradient tanks may be: (i) rectangular chambers that produce a horizontal thermal gradient, (ii) cylindrical chambers that produce a vertical thermal gradient, (iii) electronic shuttleboxes that produce a horizontal gradient controlled by the movement of organisms, or (iv) annular chambers (e.g. Ybarrondo, 1995; Hernández-Rodríguez et al., 2002; Myrick et al., 2004; Marek and Gvoždík 2012; Reiser et al., 2013). Horizontal tanks provide uniform light intensity, shallow water depths $(<3 \mathrm{~cm})$ to prevent the effects of thermal stratification (Myrick et al., 2004), and a uniform bottom/attachment surface onto which organisms may attach and move (e.g. aquatic insects) or walk on (e.g. newts). A typical and fairly simple horizontal gradient tank that generated a stable linear thermal gradient of $10^{\circ} \mathrm{C}$ to $50^{\circ} \mathrm{C}$ (Ybarrondo, 1995) comprised a shallow, rectangular plastic tank, with heating and cooling elements at either end. Normoxic conditions and circulation of water were provided by means of air bubbling fixtures buried in the gravel substrate along the length of the tank. Vertical gradient tanks are well suited to studies on free-swimming organisms (e.g. zooplankton, fish) and are able to investigate the effects of thermal stratification, deep waters, and negligible currents. However, vertical gradient tanks may suffer from interacting effects such as disproportionate light intensities and water pressures, especially in larger systems (Myrick et al., 2004). Similarly, shuttleboxes, while they allow the organism to regulate the temperature in a horizontal gradient, may incur problems with being shallow and with features that provide different amounts of perceived cover to organisms (Myrick et al., 2004). Thermal gradient tanks range in complexity and cost, although simple horizontal ones are relatively cost-effective, portable and easy to use.

\section{Artificial streams}

Artificial streams which replicate natural stream conditions, where certain variables may still be controlled, represent some of the most expensive and elaborate experimental setups (Warren and Davis, 1971). Artificial stream channels are commonly dug adjacent to natural streams from which they receive constant regulated inflows of water. Water channelled to the artificial stream may be heated, chemically treated or enriched, depending on the experimental focus. The streams may be designed to provide combinations of habitat types (e.g. rifflepool-runs), to have a constant known gradient, be lined such that the effects of natural/artificial groundwater inflows may either be included or excluded, and have specific substrate type and size. Aquatic invertebrates naturally colonise these systems from the adjacent natural stream or through drift, or are manually stocked (Hogg and Williams, 1996). These systems are sampled regularly, as would natural streams, over long time frames, to investigate questions related to ecological effects of temperature (e.g. species richness, composition, density and distribution, and also secondary productivity, growth rates, voltinism, fecundity, and emergence). Artificial streams are commonly linked to institutions that have a dedicated river system(s) or experimental area(s) that provides a secure longterm facility for undertaking experiments.

\section{CONCLUSIONS}

This paper provides an overview of the sublethal effects of temperature on aquatic organisms and outlines methods for estimating these effects. The choice of laboratory or field setup ultimately depends on the objectives of the study, logistical constraints and available finances. While laboratory studies have been questioned as to their usefulness and potential for application to complex natural conditions (Hynes, 1970; Hogg and Williams, 1996), they can provide a suite of valuable information relating to specific variables. Further, it is often the combination of laboratory and field studies that yields more information than either method alone (Hynes, 1970; Brittain, 1982). Even the simplest designs may produce results, which when interpreted in the context of natural systems, provide useful information on the biotic responses of aquatic organisms to changes in water temperature. Experiments that provide insight into the thermal requirements of individual organisms allow one to make predictions about likely consequences of thermal changes. For example, investigations into hatching temperatures for species, which may easily be undertaken using water-filled containers (non-aerated or aerated), may be used in conjunction with estimates of thermal limits, to predict range shifts in response to increases in water temperature (Rivers-Moore et al., 2013b). Upper thermal limits, which are easily estimated using aerated containers and aquarium heaters set to provide a minimum of 5 thermal environments, may be used to calculate biological temperature thresholds and for the setting of defendable, biologically-relevant water temperature guidelines for lotic systems (Dallas and Ketley, 2011; Dallas and Rivers-Moore, 2012; Dallas et al. 2015). Field studies investigating life-history information provide valuable insight into current and likely future impact of changes in water temperature on individuals and communities (Ross-Gillespie, 2014). These examples of simple laboratory experiments and field surveys undertaken in South Africa over the last 5 years, highlight the enormous value in undertaking studies on thermal responses. Furthermore, this knowledge contributes to the development of water temperature guidelines for lotic systems, which is vital for the management and protection of aquatic ecosystems in the face of ongoing anthropogenic impacts on river systems, including those resulting from global climate change.

\section{ACKNOWLEDGMENTS}

The Water Research Commission provided funding for this research (project K5/2182) - thanks to Mr Bonani Madikizela for facilitation of this research and Mrs Una Wium for administrative support. Thanks to our two reviewers for their insightful and useful comments on the manuscript.

\section{REFERENCES}

ABRAMS PA, OLOF L, NYLIN S and WIKLUND C (1996) The effect of flexible growth rates on optimal sizes and development times in a seasonal environment. Am. Nat. 147 381-395.

ACUÑA V, WOLF A, UEHLINGER U and TOCKNER K (2008) Temperature dependence of stream benthic respiration in an Alpine river network under global warming. Freshwater Biol. 53 2076-2088.

ALDERDICE DF and VELSEN FPJ (1978) Relation between temperature and incubation time for eggs of Chinook Salmon (Oncorhynchus tshawytscha). J. Fish. Res. Board Can. 35 69-75.

ANGILLETTA JR MJ, NIEWIAROWSKI PH and NAVAS CA (2002) The evolution of thermal physiology in ectotherms. J. Therm. Biol. 27 249-268. 
ANGILLETTA JR MJ, STEURY TD and SEARS MW (2004) Temperature, growth rate, and body size in ectotherms: fitting pieces of a life-history puzzle. Integ. Comp. Biol. 44 498-509.

ANGILLETTA JR MJ (2006) Estimating and comparing thermal performance curves. J. Therm. Biol. 31 541-545.

ATKINSON D (1995) Effects of temperature on the size of aquatic ectotherms: exceptions to the general rule. J. Therm. Biol. 20 61-74.

ATKINSON D, BEGON M and FITTER AH (1994) Temperature and organism size - a biological law for ectotherms? Adv. Ecol. Res. 25 $1-58$.

BAKER RL and FELTMATE BW (1989) Depth selection by larval Ischnura verticalis (Odonata: Coenagrionidae): effects of temperature and food. Freshwater Biol. 22 169-175.

BARBER SB (1961) Chemoreception and thermoreception. In: Waterman TH (ed.) The Physiology of Crustacea ( $2^{\text {nd }}$ edn). Academic Press, New York. 109-131.

BEER WN and ANDERSON JJ (2001) Effect of spawning day and temperature on salmon emergence: interpretations of a growth model for Methow River Chinook. Can. J. Fish. Aq. Sci. 58 943-949.

BEITINGER T, BENNET W and McCAULEY R (2000) Temperature tolerances of North American freshwater fishes exposed to dynamic changes in temperature. Environ. Biol. Fish. 58 237-275.

BEKLIOGLU M, GOZEN AG, YILDIRIM F, ZORLU P and ONDE $S$ (2008) Impact of food concentration on diel vertical migration behaviour of Daphnia pulex under fish predation risk. Hydrobiol. $614321-327$

BELL J (2006) The assessment of thermal impacts on habitat selection growth reproduction and mortality in brown trout (Salmo trutta L.): A review of the literature. Rep. No. EPA GRANT \#WS 97512701-0. Applied Ecological Services Inc., Minnesota.

BENKE AC and HURYN AD (2006) Secondary production of macroinvertebrates. In: Hauer FR and Lamberti GA (eds) Methods in Stream Ecology ( $2^{\text {nd }}$ edn). Academic Press/Elsevier, Burlington, MA. 691-710.

BENKE AC, ARSDALL TCV, JR, GILLESPIE DM and PARRISH FK (1984) Invertebrate productivity in a subtropical blackwater river the importance of habitat and life history. Ecol. Mono. 54 25-63.

BERRIGAN D and KOELLA JC (1994) The evolution of reaction norms: simple models for age and size at maturity. J. Evol. Biol. 7 $549-566$.

BOTT TL (2006) Primary productivity and community respiration. In Hauer FR and Lamberti GA (eds) Methods in Stream Ecology $\left(2^{\text {nd }}\right.$ edn). Academic Press/Elsevier, Burlington, MA. 533-556.

BOUBÉE J, SCHICKER K and STANCLIFF A (1991) Thermal avoidance in inanga Galaxias maculatus (Jenyns) from the Waikato River New Zealand. N. Z. J. Mar. Freshwater Res. 25 177-180.

BRITTAIN JE (1975) The life cycle of Baetis macani Kimmins (Ephemeridae) in a Norwegian mountain biotope. Insect Syst. Evol. 6 47-51.

BRITTAIN JE (1976) Experimental studies on nymphal growth in Leptophlebia vespertina (L.) (Ephemeroptera). Freshwater Biol. 6 445-449.

BRITTAIN JE (1982) Biology of mayflies. Ann. Rev. Entomol. 27 119-147.

BRITTAIN JE (1983) The influence of temperature on nymphal growth rates in mountain stoneflies (Plecoptera). Ecology 64 440-446.

BRITTAIN JE (1990) Life history strategies in Ephemeroptera and Plecoptera. In: Campbell IC (ed.) Mayflies and Stoneflies: Life Histories and Biology. Kluwer Academic Publishers, Dordrecht. 1-12.

BRITTAIN JE (1991) Effect of temperature on egg development in the Australian stonefly genus Austrocercella Illies (Plecoptera: Notonemouridae). Aust. J. Mar. Freshwater Res. 42 107-114.

BRITTAIN JE (1995) Egg development in Australian mayflies (Ephemeroptera). In: Corkum LD and Ciborowski JJH (eds) Current Directions in Research on Ephemeroptera. Canadian Scholars' Press Inc., Toronto. 307-316.

BRITTAIN JE and CAMPBELL I (1991) The effect of temperature on egg development in the Australian mayfly genus Coloburiscoides (Ephemeroptera: Coloburiscidae) and its relationship to distribution and life history. J. Biogeogr. 18 231-235.

BRITTAIN JE and BILDENG R (1995) Life cycle of Arctopsyche ladogensis (trichoptera) in a regulated Norwegian river. Reg. Riv. Res. Manage. 10 71-79.
BRITTAIN JE and EIKELAND TJ (1988) Invertebrate drift - a review. Hydrobiol. 166 77-93.

BRITTAIN JE and LILLEHAMMER A (1987) Variability In the rate of egg development of the stonefly, Nemoura cinerea (Plecoptera). Freshwater Biol. 17 565-568.

BRITTAIN JE and SALTVEIT SJ (1989) A review of the effect of river regulation on mayflies (Ephemeroptera). Reg. Riv. Res. Manage. 3 191-204.

BRITTAIN JE, LILLEHAMMER A and SALTVEIT SJ (1984) The effect of temperature on intraspecific variation in egg biology and nymphal size in the stonefly, Capnia atra (Plecoptera). J. Anim. Ecol. 53 161-169.

BROWN LE, HANNAH DM and MILNER AM (2005) Spatial and temporal water column and streambed temperature dynamics within an alpine catchment: implications for benthic communities. Hydrol. Process. 19 1585-1610.

BRUNGS W (1971) Chronic effects of constant temperature on the fathead minnow, Pimephales promelas rafinesqe. Trans. Am. Fish. Soc. 100 659-664.

BURKS RL, LODGE DM, JEPPESEN E and LAURIDSEN TL (2002) Diel horizontal migration of zooplankton: costs and benefits of inhabiting the littoral. Freshwater Biol.47 343-365.

BURY RB, NEBEKER AV and ADAMS MJ (2000) Response of hatchling and yearling turtles to thermal gradients: comparison of Chelydra serpentina and Trachemys scripta. J. Therm. Biol. 25 221-225.

BUTLER MG (1984) Life histories of aquatic insects. In: Resh VH and Rosenberg DW (eds) Ecology of Aquatic Insects. Praeger Publishers, New York. 289-322.

CABANAC M (1979) Sensory pleasure. Q. Rev. Biol. 54 1-29.

CAISSIE D (2006) The thermal regime of rivers: a review. Freshwater Biol. 51 1389-1406.

CAISSIE D and GIBERSON DJ (2003) Temporal variation of stream and intragravel water temperatures in an Atlantic Salmon (Salmo salar) spawning area in Catamaran Brook (New Brunswick). Can. Tech. Rep. Fish. Aquat. Sci. 2464.

CAMPBELL I (1986) Life histories of some Australian Siphlonurid and Oligoneurid mayflies (Insecta: Ephemeroptera). Aust. J. Mar. Freshwater Res. 37 261-288.

CAQUET T, LAGADIC L and SHEFFIELD S (2000) Mesocosms in ecotoxicology (1): Outdoor aquatic systems. Rev. Environ. Contam. Toxicol. $1651-38$

CASE TJ (1981) Niche packing and coevolution in competition communities. Proc. Natl. Acad. Sci. U.S.A. 78 5021-5025.

CASTELLA E, ADALSTEINSSON H, BRITTAIN JE, GISLASON GM, LEHMANN A, LENCIONI V, LODS-CROZET B, MAIOLINI B, MILNER AM, OLAFSSON JS, SALTVEIT SJ and SNOOK DL (2001) Macrobenthic invertebrate richness and composition along a latitudinal gradient of European glacier-fed streams. Freshwater Biol. 46 1811-1831.

CHERRY D and CAIRNS J (1982) Biological monitoring - Part V: preference and avoidance studies. Water Res. 16 263-301.

CLEMENTS WH, CADMUS P and BRINKMAN SF (2013) Responses of aquatic insects to $\mathrm{Cu}$ and $\mathrm{Zn}$ in stream microcosms: understanding differences between single species tests and field responses. Environ. Sci. Technol. 47 7506-7513.

CLIFFORD HF, HAMILTON H and KILLINS BA (1979) Biology of the mayfly Leptophlebia cupida (Say) (Ephemeroptera: Leptophlebiidae). Can. J. Zool. 57 1026-1045.

CLIFFORD HF (1982) Life cycles of mayflies (Ephemeroptera), with special reference to voltinism. Quaest. Entomol. 18 15-90.

COMBS BD. 1965. Effect of temperature on the development of salmon eggs. The Progressive Fish-Culturist 27 134-137.

CONNOLLY NM, CROSSLAND MR and PEARSON RG (2004) Effect of low dissolved oxygen on survival, emergence, and drift of tropical stream macroinvertebrates. J. N. Am. Benthol. Soc. 23 251-270.

CORKUM LD, CIBOROWSKI JJH and POULIN RG (1997) Effects of emergence date and maternal size on egg development and sizes of eggs and first-instar nymphs of a semelparous aquatic insect. Oecologia 111 69-75.

COUTANT CC (1987) Thermal preference: when does an asset become a liability? Environ. Biol. Fish. 18 161-172. 
COUTANT CC (1977) Compilation of Temperature Preference Data. J. Fish. Res. Board Can. 34 739-745.

CRISP D (1990) Water temperature in a stream gravel bed and implications for salmonid incubation. Freshwater Biol. 23 601-612.

CUMMINS KW (1974) Structure and function of stream ecosystems. BioScience 24 631-641.

DALLAS HF (2008) Water temperature and riverine ecosystems: An overview of knowledge and approaches for assessing biotic responses, with special reference to South Africa. Water SA 34 393-404.

DALLAS H and DAY J (2004) The effect of water quality variables on aquatic ecosystems: a review. WRC Report No. TT 224/04. Water Research Commission, Pretoria.

DALLAS HF and KETLEY ZA (2011) Upper thermal limits of aquatic macroinvertebrates: comparing Critical Thermal Maxima with 96-LT ${ }_{50}$ values. J. Therm. Biol. 36 322-327.

DALLAS HF and RIVERS-MOORE N (2012) Critical Thermal Maxima of aquatic macroinvertebrates - towards identifying bioindicators of thermal alteration. Hydrobiologia 679 61-76.

DALLAS HF and RIVERS-MOORE NA (2012) Water temperatures and the Reserve. WRC Report No. 1799/1/12. Water Research Commission, Pretoria.

DALLAS HF and RIVERS-MOORE N (2014) Ecological consequences of global climate change for freshwater ecosystems in South Africa. S. Afr. J. Sci. $11048-58$.

DALLAS HF, RIVERS-MOORE NA, ROSS-GILLESPIE V, RAMULIFHO P and REIZENBERG J (2015) Adaptability and vulnerability of riverine biota to climate change - developing tools for assessing biological effects. WRC Report No. K5/2182. Water Research Commission, Pretoria.

DAS T, PAL AK, CHAKRABORTY SK, MANUSH SM, SAHU NP and MUKHERJEE SC (2005) Thermal tolerance, growth and oxygen consumption of Labeo rohita fry (Hamilton, 1822) acclimated to four temperatures. J. Therm. Biol. 30 378-383.

DE MOOR FC (1982). Determination of the number of instars and size variation in the larvae and pupae of Simulium chutteri Lewis 1965 (Diptera: Simuliidae) and some possible bionomical implications. Can. J. Zool. 60 1374-1382.

DE MOOR FC (1994). Aspects of the life history of Simulium chutteri and $S$. bovis (Diptera;

Simuliidae) in relation to changing environmental conditions in South African rivers. Verh. Internat. Verein. Limnol. 25 1817-1821.

DITSCHE-KURU P, BARTHLOTT W and KOOP JHE (2012) At which surface roughness do claws cling? Investigations with larvae of the running water mayfly Epeorus assimilis (Heptageniidae, Ephemeroptera). Zoology 115 379-388.

DOWNES BJ, LAKE PS and SCHREIBER ESG (1993) Spatial variation in the distribution of stream invertebrates: implications of patchiness for models of community organization. Freshwater Biol. 30 119-132.

DOWNING JA (1984) Assessment of secondary production: the first step. A manual on methods for the assessment of secondary productivity in fresh waters. IBP Handbook 17. Blackwell Scientific Publishers, Oxford, USA. 1-18.

DURANCE I and ORMEROD SJ (2007) Climate change effects on upland stream macroinvertebrates over a 25 -year period. Glob. Change Biol. 13 942-957.

EADY BR, RIVERS-MOORE NA and HILL TR (2013) Relationship between water temperature predictability and aquatic macroinvertebrate assemblages in two South African streams. Afr. J. Aquat. Sci. 38 163-174

EBERSOLE J, LISS W and FRISSELL C (2001) Relationship between stream temperature thermal refugia and rainbow trout Oncorhynchus mykiss abundance in arid-land streams in the northwestern, United States. Ecol. Freshwater Fish 10 1-10.

ELLIOTT JM (1972) Effect of temperature on the time of hatching in Baetis rhodani (Ephemeroptera: Baetidae). Oecologia 9 47-51.

ELLIOTT JM (2000) Pools as refugia for brown trout during two summer droughts: trout responses to thermal and oxygen stress. J. Fish Biol. 56 938-948.

ELLIOTT JM (1984) Hatching time and growth of Nemurella pictetii (Plecoptera: Nemouridae) in the laboratory and a Lake District stream. Freshwater Biol. 14 491-499.
ELLIOTT JM (1988) Egg hatching and resource partitioning in stoneflies (Plecoptera): ten british species in the family Nemouridae. $J$. Anim. Ecol. 57 201-215.

ELLIOTT JM (2009) Inter- and intra-specific differences in the number of larval instars in British populations of 24 species of stoneflies (Plecoptera). Freshwater Biol. 54 1271-1284.

ELLIOTT JM (2013) Contrasting dynamics from egg to adult in the life cycle of summer and overwintering generations of Baetis rhodani in a small stream. Freshwater Biol. 58 866-879.

FICKE AD, MYRICK CA and HANSEN LJ (2007) Potential impacts of global climate change on freshwater fisheries. Rev. Fish Biol. Fish. 17 581-613.

FILIPE AF, LAWRENCE JE and BONADA N (2013) Vulnerability of stream biota to climate change in mediterranean climate regions: a synthesis of ecological responses and conservation challenges. Hydrobiologia 719 331-352.

FJELLHEIM A and RADDUM GG (2008) Growth and voltinism in the aquatic insects of a regulated river subject to groundwater inflows. Riv. Res. Applic. 24 710-719.

FONDS M (1979) Laboratory observations on the influence of temperature and salinity on development of the eggs and growth of the larvae of Solea solea (Pisces). Mar. Ecol. Prog. Ser. 1 91-99.

FREDERICH M and PÖRTNER HO (2000) Oxygen limitation of thermal tolerance defined by cardiac and ventilatory performance in spider crab, Maja squinado. Am. J. Physiol. 279 1531-1538.

FREY DG (1982) Contrasting strategies of gamogenesis in northern and southern populations of Cladocera. Ecology 63 223-241.

FRIBERG N, DYBKJAER JB, OLAFSSON JS, GISLASON GM, LARSEN SE and LAURIDSEN TL (2009) Relationships between structure and function in streams contrasting in temperature. Freshwater Biol. 54 2051-2068.

GARDNER B, SULLIVAN P and LEMBOR A (2003) Predicting stream temperatures: geostatistical model comparison using alternative distance metrics. Can. J. Fish. Aquat. Sci. 60 344-351.

GASITH A and RESH VH (1999) Streams in Mediterranean climate regions: abiotic influences and biotic responses to predictable seasonal events. Annu. Rev. Ecol. Syst. 30 51-81.

GERALD G and SPEZZANO C (2005) The influence of chemical cues and conspecific density on the temperature selection of a freshwater snail (Melanoides tuberculata). J. Therm. Biol. 20 237-245.

GERRITSEN J (1982) Behavioral response of Daphnia to rate of temperature change: possible enhancement of vertical migration. Limnol. Ocean. 27 254-261.

GIBERSON DJ and ROSENBERG DM (1992) Effects of temperature, food quantity, and nymphal rearing density on life-history traits of a northern population of Hexagenia (Ephemeroptera: Ephemeridae). J. N. Am. Benthol. Soc. 11 181-193.

GILLOOLY JF and DODSON SI (2000) The relationship of egg size and incubation temperature to embryonic development time in univoltine and multivoltine aquatic insects. Freshwater Biol. 44 595-604.

GILLOOLY JF, CHARNOV EL, WEST GB, SAVAGE VM and BROWN $\mathrm{JH}$ (2002) Effects of size and temperature on developmental time. Nature 417 70-73.

GOLUBKOV SM, TIUNOVA TM and KOCHARINA SL (1992) Dependence of the respiration rate of aquatic insects upon the oxygen concentration in running and still water. Aquat. Insects $\mathbf{1 4}$ 137-144. DOI:

$10.1080 / 01650429209361476$.

GOOSEFF MN, STRZEPEK K and CHAPRA SC (2005) Modeling the potential effects of climate change on water temperature downstream of a shallow reservoir, lower Madison river, MT. Climatic Change 68 331-353.

GORSKI PR and DODSON SI (1996) Free-swimming Daphnia pulex can avoid following Stoke's law. Limnol. Ocean. 41 1815-1821.

GREEN J (1966) Seasonal Variation in Egg Production by Cladocera. J. Anim. Ecol. 35 77-104.

GREIG HS, KRATINA P, THOMPSON PL, PALEN WJ, RICHARDSON JS and SHURIN JB (2012) Warming, eutrophication, and predator loss amplify subsidies between aquatic and terrestrial ecosystems. Glob. Change Biol. 18 504-514.

GULATI RD (1974) Laboratory methods in secondary production. Hydrobiol. Bull. 8 255-268. 
GUSTAFSON MP (2008) Effects of thermal regime on mayfly assemblages in mountain streams. Hydrobiologia 605 235-246.

HAIDEKKER A and HERING D (2008) Relationship between benthic insects (Ephemeroptera, Plecoptera, Coleoptera, Trichoptera) and temperature in small and medium-sized streams in Germany: a multivariate study. Aquat. Ecol. 42 463-481.

HARPER MP and PECKARSKY BL (2006) Emergence cues of a mayfly in a high-altitude stream ecosystem: potential response to climate change. Ecol. Appl. 16 612-621.

HARPER PP and HYNES HBN (1970) Diapause in the nymphs of Canadian winter stoneflies. Ecology 51 925-927.

HARPER PP (1973) Emergence, reproduction, and growth of setipalpian Plecoptera in southern Ontario. Oikos 24 94-107.

HART RC and RAYNER NA (1994) Temperature-related distributions of Metadiaptomus and Tropodiaptomus (Copepoda: Calanoida), particularly in southern Africa. Hydrobiologia 272 77-86.

HAW KINS CP (1986) Variation in individual growth rates and population densities of ephemerellid mayflies. Ecology 67 1384-1395.

HEIMAN DR and KNIGHT AW (1975) The influence of temperature on the bioenergetics of the carnivorous stonefly nymph, Acroneuria californica Banks (Plecoptera: Perlidae). Ecology 56 105-116.

HERNÁNDEZ-RODRÍGUEZ M and BÜCKLE-RAMIREZ LF (1997) Thermal preference area for Macrobrachium tenellum in the context of global climatic change. J. Therm. Biol. 22 309-313.

HERNÁNDEZ-RODRÍGUEZ M, BÜCKLE-RAMIREZ LF and ESPINA S (2002) Temperature preference and acclimation in Poecilia sphenops (Pisces, Poeciliidae). Aquacult. Res 33 933-940.

HOGG ID and WILLIAMS DD (1996) Response of stream invertebrates to a global-warming thermal regime: an ecosystem-level manipulation. Ecology 77 395-407.

HUEY RB and STEVENSON RD (1979) Integrating thermal physiology and ecology of ectotherms: a discussion of approaches. Am. Zool. 19357-366.

HUMPESCH UH (1978) Preliminary notes on the effect of temperature and light-condition on the time of hatching in some Heptageniidae (Ephemeroptera). In: Proceedings of the Internationale Vereinigung fur Theoretische und Angewandte Limnologie Congress, 1977, Denmark.

HUMPESCH UH (1979) Life cycles and growth rates of Baetis spp. (Ephemeroptera: Baetidae) in the laboratory and in two stony streams in Austria. Freshwater Biol. 9 467-479.

HUMPESCH UH (1980) Effect of temperature on the hatching time of parthenogenetic eggs of five Ecdyonurus spp. and two Rhithrogena spp. (Ephemeroptera) from Austrian streams and english rivers and lakes. J. Anim. Ecol. 49 927-937.

HUMPESCH UH (1981) Effect of temperature on larval growth of Ecdyonurus dispar (Ephemeroptera: Heptageniidae) from two English lakes. Freshwater Biol. 11 441-457.

HUMPESCH UH (1984) Egg development of non-diapausing exopterygote aquatic insects occurring in Europe. Österreich. Akad. Wiss. Math. Natur. Kl. 193 329-341.

HUMPESCH UH and ELLIOTT JM (1980) Effect of temperature on the hatching time of eggs of three Rhithrogena spp. (Ephemeroptera) from Austrian streams and an English stream and river. J. Anim. Ecol. 49 643-661.

HURYN AD and WALLACE JB (2000) Life history and production of stream insects. Annu. Rev. Entomol. 45 83-110.

HUTCHINSON GE (1981) Thoughts on aquatic insects. BioScience 31 495-500.

HUTCHISON VH and MANESS JD (1979) The role of behavior in temperature acclimation and tolerance in ectotherms. Am. Zool. 19367-384.

HUTCHISON VH AND SPRIESTERSBACH KK (1986) Diel and seasonal cycles of activity and behavioral thermoregulation in the salamander Necturus maculosus. Copeia 1986 612-618.

HYNES HBN. 1970. The ecology of running waters. Liverpool University Press, United Kingdom.555 pp.

JACKSON DA, PERES-NETO PR and OLDEN JD (2001) What controls who is where in freshwater fish communities - the roles of biotic, abiotic, and spatial factors. Can. J. Fish. Aquat. Sci. 58 157-170.

JACKSON JK and SWEENEY BW (1995) Egg and larval development times for 35 species of tropical stream insects from Costa Rica. J. N. Am. Benthol. Soc. 14 115-130.
JACOBSEN D and FRIBERG N (1997) Macroinvertebrate communities in Danish streams: the effect of riparian forest cover. In: Sand-Jensen K and Pederson O (eds) Freshwater Biology: Priorities and Development in Danish Research. Gad, Copenhagen. 208-222.

JACOBSEN D, DANGLES O, ANDINO P, ESPINOSA R, HAMERLÍK L and CADIER E (2010) Longitudinal zonation of macroinvertebrates in an Ecuadorian glacier-fed stream: do tropical glacial systems fit the temperate model? Freshwater Biol. 55 1234-1248.

JACOBSEN D, SCHULTZ R AND ENCALADA A (1997) Structure and diversity of stream invertebrate assemblages: the influence of temperature with altitude and latitude. Freshwater Biol. 38 247-261.

JACOBSEN D (2004) Contrasting patterns in local and zonal family richness of stream invertebrates along an Andean altitudinal gradient. Freshwater Biol. 49 1293-1305.

JONES EA, LUCEY KS and ELLERBY DJ (2007) Efficiency of labriform swimming in the bluegill sunfish (Lepomis macrochirus). J. Exp. Biol. 210 3422-3429.

KAVALIERS M (1980) A circadian rhythm of behavioural thermoregulation in a freshwater gastropod, Helisoma trivolis. Can. J. Zool. 58 2152-2155.

KAVALIERS M (1981) Rhythmic thermoregulation in larval cranefly (Diptera: Tipulidae). Can. J. Zool. 59 555-558.

KEEN R (1979) Effects of fluctuating temperature on duration on egg development of Chydorus sphaericus (Cladocera, Crustacea). J. Therm. Biol. 4 5-8.

KELLER A (1975) Die drift und ihre ökologische bedeutung. Schweiz. Z. Hydrol. 37 294-331.

KENDRICK MR and BENSTEAD JP (2013) Temperature and nutrient availability interact to mediate growth and body stoichiometry in a detritivorous stream insect. Freshwater Biol. 58 1820-1830.

KHOO SG. 1964. Studies on the biology of stoneflies. PhD Thesis, University of Liverpool.

KIEFFER JD and COOKE SJ (2009) Physiology and organismal performance of centrarchids. In: Cooke SJ and Philipp DP (eds) Centrarchid Fishes: Diversity, Biology, and Conservation. WileyBlackwell, West Sussex, UK. 207-263.

KNISPEL S, SARTORI M and BRITTAIN JE (2006) Egg development in the mayflies of a Swiss glacial floodplain. J. N. Am. Benthol. Soc 25 430-443.

KOWNACKA M and KOWNACKI A (1972) Vertical distribution of zoocenoses in the streams of the Tatra, Caucasus and Balkan Mts. Verh. Int. Ver. Theor. Angew. Limnol. 16 742-750.

LANGFORD T (1990) Ecological effects of thermal discharges. Elsevier Applied Science, London. 468 pp.

LANGFORD TE and ASTON RJ (1972) The ecology of some British rivers in relation to warm water discharges from power stations. Proc. R. Soc. B Biol Sci. 180 407-419.

LEGGOTT M and PRITCHARD G (1986) Thermal preference and activity thresholds in populations of Argia vivida (Odonata: Coenagrionidae) from habitats with different thermal regimes. Hydrobiologia 140 85-92.

LILLEHAMMER A, BRITTAIN JE, SALTVEIT SJ and NIELSEN PS (1989) Egg development, nymphal growth and life cycle strategies in Plecoptera. Ecography 12 173-186.

LUTTERSCHMIDT WI and HUTCHISON VH (1997) The critical thermal maximum: history and critique. Can. J. Zool. 75 1561-1574.

MACARTHUR R (1970) Species packing and competitive equilibrium for many species. Theor. Popul. Biol. 1 1-11.

MANUSH SM, PAL AK, CHATTERJEE N, DAS T and MUKHERJEE SC (2004) Thermal tolerance and oxygen consumption of Macrobrachium rosenbergii acclimated to three temperatures. J. Therm. Biol. 29 15-19.

MAREK V and GVOŽDÍK L (2012) The insensitivity of thermal preferences to various thermal gradient profiles in newts. J. Ethol. 30 $35-41$.

MCCULLOUGH DA, BARTHOLOW JM, JAGER HTI, BESCHTA RL, CHESLAK EF, DEAS ML, EBERSOLE JL, FOOTT JS, JOHNSON SL, MARINE KR, MESA MG, PETERSEN JH, SOUCHON Y, TIFFAN KF and WURTSBAUGH WA (2009) Research in thermal biology: burning questions for coldwater stream fishes. Rev. Fish. Sci. 17 90-115. 
MCINTIRE CD, GARRISON RL, PHINNEY HK and WARREN CE. 1964. Primary production in laboratory streams. Limnol. Ocean. 9 92-102.

MCMAHON RF (1975) Effects of artificially elevated water temperatures on the growth, reproduction and life cycle of a natural population of Physa virgata Gould. Ecology 56 1167-1175.

MINSHALL GW, PETERSEN RC, JR. and NIMZ CF (1985) Species richness in streams of different size from the same drainage basin. Am. Nat. 125 16-38.

MITCHELL CP (1989) Laboratory culture of Galaxias maculatus and potential applications. N. Z. J. Mar. Freshwater Res. 23 325-336.

MOSLEY M (1983) Variability of water temperatures in the braided Ashley and Rakaia rivers. N. Z. J. Mar. Freshwater Res. 17 331-342.

MYRICK CA, FOLGNER DK and CECH JJ (2004) An annular chamber for aquatic animal preference studies. Trans. Am. Fish. Soc. 133 427-433.

NEBEKER A (1971a) Effect of water temperature on nymphal feeding rate emergence and adult longevity of the stonefly Pteronarcys dorsata. J. Kansas Entomol. Soc. 44 21-26.

NEBEKER A (1971b) Effect of high winter water temperatures on adult emergence of aquatic insects. Water Res. 5 77-783.

NYLIN S and GOTTHARD K (1998) Plasticity in life-history traits. Annu. Rev. Entomol. 43 63-83.

OLDMEADOW DF, LANCASTER J and RICE SP (2010) Drift and settlement of stream insects in a complex hydraulic environment. Freshwater Biol. 55 1020-1035.

ORMEROD SJ, RUNDLE SD, WILKINSON SM, DALY GP, DALE KM and JUTTNER I (1994) Altitudinal trends in the diatoms, bryophytes, macroinvertebrates and fish of a Nepalese river system. Freshwater Biol. 32 309-322.

PECKARSKY BL and COWAN CA (1991) Consequences of larval intraspecific competition to stonefly growth and fecundity. Oecologia 88 277-288

PERRY SA, PERRY WB and STANFORD JA (1987) Effects of thermal regime on size, growth rates and emergence of two species of stoneflies (Plecoptera: Taeniopterygidae, Pteronarcyidae) in the Flathead River, Montana. Am. Midl. Nat. 117 83-93.

PETTERSSON A, PICKOVA J and BRÄNNÄS E (2010) Swimming performance at different temperatures and fatty acid composition of Arctic charr (Salvelinus alpinus) fed palm and rapeseed oils. Aquaculture 300 176-181.

PÖCKL M and TIMISCHL W (1990) Comparative study of mathematical models for the relationship between water temperature and brood development time of Gammarus fossarum and G. roeseli (Crustacea: Amphipoda). Freshwater Biol. 23 433-440.

PÖCKL M (1992) Effects of temperature, age and body size on moulting and growth in the freshwater amphipods Gammarus fossarum and G. roeseli. Freshwater Biol. 27 211-225.

POWER ME, STOUT RJ, CUSHING CE, HARPER PP, HAUER FR, MATTHEWS WJ, MOYLE PB, STATZNER B and BADGEN IRWD (1988) Biotic and abiotic controls in river and stream communities. J. N. Am. Benthol. Soc. 7 456-479.

PRITCHARD G, HARDER LD and MUTCH RA (1996) Development of aquatic insect eggs in relation to temperature and strategies for dealing with different thermal environments. Biol. J. Linn. Soc. $\mathbf{5 8}$ 221-244.

RADDUM GG (1985) Effects of winter warm reservoir release on ben thic stream invertebrates. Hydrobiologia 122 105-111.

RADER RB and WARD JV (1989) Influence of impoundments on mayfly diets, life histories, and production. J. N. Am. Benthol. Soc. 8 64-73.

RAHEL FJ and OLDEN JD (2008) Assessing the effects of climate change on aquatic invasive species. Conserv. Biol. 22 521-533.

REISER S, TEMMING A, ECKHARDT A and HERRMANN J-P (2013) Automation and critical evaluation of an annular chamber for aquatic ectotherm temperature preference experiments. Meth. Ecol. Evol. 4 531-541.

RESH VH and ROSENBERG DM (2010) Recent trends in life-history research on benthic macroinvertebrates. J. N. Am. Benthol. Soc. 29 207-219.

REYNOLDS SK and BENKE AC (2005) Temperature-dependent growth rates of larval midges (Diptera: Chironomidae) from a southeastern U.S. stream. Hydrobiologia 544 69-75.
RICHARDSON J, BOUBÉE J and WEST D (1994) Thermal tolerance and preference of some native New Zealand freshwater fish. N. Z. J. Mar. Freshwater Res. 28 399-407.

RIGLER FH and DOWNING JA (1984) The calculation of secondary productivity. In: Downing JA and Rigler FH (eds) A Manual on Methods for the Assessment of Secondary Productivity in Fresh Waters ( $2^{\text {nd }}$ edn). IBP Handbook 17. Blackwell, Sussex. 19-58.

RIVERS-MOORE NA, DALLAS HF and MORRIS C (2013a) Towards setting environmental water temperature guidelines: A South African example. J. Environ. Manage. 128 380-392.

RIVERS-MOORE NA, DALLAS HF and ROSS-GILLESPIE V (2013b) Life history does matter in assessing potential ecological impacts of thermal changes on aquatic macroinvertebrates. Riv. Res. Applic. 29 1100-1109.

ROFF DA (1992) Evolution of Life Histories: Theory and Analysis. Chapman and Hall, New York.

ROHDE K (1992) Latitudinal gradients in species diversity: the search for the primary cause. Oikos 65 514-527.

ROSS-GILLESPIE V (2014) Effects of water temperature on lifehistory traits of selected South African aquatic insects. $\mathrm{PhD}$ thesis, University of Cape Town, Cape Town.

ROSSETTIA Y and CABANAC M (2006) Light versus temperature: An intersensitivity conflict in a gastropod (Lymnaea auricularia). J. Therm. Biol. 31 514-520.

ROSSETTI Y, ROSSETTI L and CABANAC M (1989) Annual oscillation of preferred temperature in the freshwater snail Lymnaea auricularia: effect of light and temperature. Anim. Behav. 37 897-907.

ROSTGAARD S and JACOBSEN D (2005) Respiration rate of stream insects measured in situ along a large altitude range. Hydrobiologia 549 79-98.

ROTVIT L and JACOBSEN D (2013) Temperature increase and respiratory performance of macroinvertebrates with different tolerances to organic pollution. Limnologica 43 510-515.

ROWE L and LUDWIG D (1991) Size and timing of metamorphosis in complex life-cycles: time constraints and variation. Ecology 72 413-427.

RYAN SM and DODSON SI (1998) Seasonal analysis of Daphnia pulicaria swimming behavior. Hydrobiologia 384 111-118.

SAVAGE AA (1986) The distribution, life cycle and production of Leptophlebia vespertina (L.) (Ephemeroptera) in a lowland lake. Hydrobiologia 133 3-19.

SCHALAU K, RINKE K, STRAILE D and PEETERS F (2008) Temp erature is the key factor explaining interannual variability of Daphnia development in spring: a modelling study. Oecologia 157 531-543.

SEMMENS D and SWEARER SE (2011) Extended incubation affects larval morphology, hatching success and starvation resistance in a terrestrially spawning fish, Galaxias maculatus (Jenyns 1842). J. Fish Biol. 79 980-990.

SHAMA L and ROBINSON CT (2006) Sex-specific life-history responses to seasonal time constraints in an alpine caddisfly. Evol. Ecol. Res. 8 169-180.

SHELDON AL (2012) Possible climate-induced shift of stoneflies in a southern Appalachian catchment. Freshwater Sci. 31 765-774.

SIBLY RM and ATKINSON D (1994) How rearing temperature affects optimal adult size in ectotherms. Funct. Ecol. 8 486-493.

SLUSARCZYK M and RYBICKA B (2011) Role of temperature in diapause response to fish kairomones in crustacean Daphnia. J. Insect. Physiol. 57 676-680.

SÖDERSTRÖM O (1988) Effects of temperature and food quality on life-history parameters in Parameletus chelifer and P. minor (Ephemeroptera): a laboratory study. Freshwater Biol .20 295-303.

SOUTHWOOD TRE (1977) Habitat, the templet for ecological strategies? J. Anim. Ecol. 46 337-365.

SOUTHWOOD TRE (1988) Tactics, strategies and templets. Oikos 52 3-18.

STATZNER B and DOLÉDEC S (2011) Phylogenetic, spatial, and species-trait patterns across environmental gradients: the case of Hydropsyche (Trichoptera) along the Loire River. Int. Rev. Hydrobiol. 96 121-140.

STEARNS SC and KOELLA JC (1986) The evolution of phenotypic plasticity in life-history traits: predictions of reaction norms for age and size at maturity. Evolution 40 893-913. 
STEARNS SC (1976) Life-history tactics: a review of the ideas. Q. Rev. Biol. 51 3-47.

STEARNS SC (1989) Trade-offs in life-history evolution. Funct. Ecol. 3 259-268.

STOUT J and VANDERMEER J (1975) Comparison of species richness for stream-inhabiting insects in tropical and mid-latitude streams. Am. Nat. 263-280.

SUTCLIFFE DW and CARRICK TR (1981) Effect of temperature on the duration of egg development, and moulting and growth in juveniles of Crangonyx pseudogracilis (Crustacea: Amphipoda) in the laboratory. Freshwater Biol. 11 511-522.

SWEENEY BW (1978) Bioenergetic and developmental response of a mayfly to thermal variation. Limnol. Ocean. 23 461-477.

SWEENEY BW and VANNOTE RL (1978) Size variation and the distribution of hemimetabolous aquatic insects: two thermal equilibrium hypotheses. Science $200444-446$.

SWEENEY BW and VANNOTE RL (1981) Ephemerella mayflies of White Clay Creek: bioenergetic and ecological relationships among six coexisting species. Ecology 62 1353-1369.

SWEENEY BW and VANNOTE RL (1984) Influence of food quality and temperature on life history characteristics of the parthenogenetic mayfly, Cloeon triangulifer. Freshwater Biol. 14 621-630.

SWEENEY BW and VANNOTE RL (1987) Geographic parthenogenesis in the stream mayfly Eurylophella funeralis in eastern North America. Ecography 10 52-59.

SWEENEY BW, JACKSON JK and FUNK DH (1995) Semivoltinism, seasonal emergence, and adult size variation in a tropical stream mayfly (Euthyplocia hecuba). J. N. Am. Benthol. Soc. 14 131-146.

SWEENEY BW, VANNOTE RL and DODDS PJ (1986) The relative importance of temperature and diet to larval development and adult size of the winter stonefly, Soyedina carolinensis (Plecoptera: Nemouridae). Freshwater Biol. 16 39-48.

SWEENEY BW (1984) Factors influencing life-history patterns of aquatic insects. In: Resh VH and Rosenberg DM (eds) The Ecology of Aquatic Insects. Praeger Publishers, New York. 56-100.

TATE K, LANCASTER D and LILE D (2006) Assessment of thermal stratification within stream pools as a mechanism to provide refuge for native trout in hot arid rangelands. Environ. Mon. Assess. 124 289-300.

TÓMASSON T, CAMBRAY J and JACKSON P (1984) Reproductive biology of four large riverine fishes (Cyprinidae) in a man-made lake Orange River South Africa. Hydrobiologia 112 179-195.

TORGERSEN C, PRICE D, LI H and MCINTOSH B (1999) Multiscale thermal refugia and stream habitat associations of chinook salmon in north-Eastern Oregon. Ecol. Appl. 9 301-319.

TOWNSEND CR (1989) The patch dynamics concept of stream community ecology. J. N. Am. Benthol. Soc. 8 36-50.

VANNOTE RL, MINSHALL GW, CUMMINGS KW, SEDELL JR and CUSHING CE (1980) The river continuum concept. Can. J. Fish. Aquat. Sci. 37 130-137.

VANNOTE R and SWEENEY BW (1980) Geographic analysis of thermal equilibria: a conceptual model for evaluating the effect of natural and modified thermal regimes on aquatic insect communities. Am. Nat. 115 667-695.

VERBERK WCEP and BILTON DT (2013) Respiratory control in aquatic insects dictates their vulnerability to global warming. Biol. Lett. 9 DOI: 10.1098/rsbl.2013.0473.
VERBERK WCEP, BILTON DT, CALOSI P and SPICER JI (2011) Oxygen supply in aquatic ectotherms: partial pressure and solubility together explain biodiversity and size patterns. Ecology 92 $1565-1572$.

VERBERK WCEP, SIEPEL H and ESSELINK H (2008) Life-history strategies in freshwater macroinvertebrates. Freshwater Biol. 53 1722-1738.

VERBERK WCEP, SOMMER U, DAVIDSON RL and VIANT MR (2013) Anaerobic metabolism at thermal extremes: a metabolomic test of the oxygen limitation hypothesis in an aquatic insect. Integr. Comp. Biol. 53 609-619.

VINSON MR and HAW KINS CP (1998) Biodiversity of stream insects: Variation at local, basin, and regional scales. Annu. Rev. Entomol. 43 271-293.

VOELZ N and MCARTHUR JV (2000) An exploration of factors influencing lotic insect species richness. Biodiv. Conserv. 9 1543-1570.

WARD JV (1985) Thermal characteristics of running waters. Hydrobiologia 125 31-46.

WARD JV and STANFORD JA (1982) Thermal responses in the evolutionary ecology of aquatic insects. Annu. Rev. Entomol. 27 97-117.

WARD JV and STANFORD JA (1983) The serial discontinuity concept of lotic ecosystems. In: Fontaine TD, III and Bartell SM (eds) Dynamics of Lotic Ecosystems. Ann Arbor Press, Michigan. 29-42.

WARREN CE and DAVIS GE (1971) Laboratory stream research: objectives, possibilities, and constraints. Annu. Rev. Ecol. Syst. 2 111-144.

WATERS TF (1972) The drift of stream insects. Annu. Rev. Entomol. 17 253-272.

WATERS TF and CRAWFORD GW (1973) Annual production of a stream mayfly population: a comparison of methods. Limnol. Oceanogr. 18 286-296.

WEBB BW, HANNAH DM, MOORE RD, BROWN LE and NOBILIS F (2008) Recent advances in stream and river temperature research. Hydrol. Process. 22 902-918.

WESNER JS (2010) Aquatic predation alters a terrestrial prey subsidy. Ecology 91 1435-1444.

WICHERT GA and LIN P (1996) Species tolerance index for maximum water temperature. Water Qual. Res. J. Can. 31 875-893.

WILLIAMS DD (1996). Environmental constraints in temporary fresh waters and their consequences for the insect fauna. J. N. Am. Benthol. Soc.15 634-650.

WOODWARD G, PERKINS DM and BROWN LE (2010) Climate change and freshwater ecosystems: impacts across multiple levels of organization. Phil. Trans. R. Soc. B 365 2093-2106.

YBARRONDO BA (1995) Habitat selection and thermal preference in two species of water scavenger beetles (Coleoptera: Hydrophilidae). Physiol. Zool. 68 749-771.

YOSHIMURA M, ISOBE Y and OISHI T (2006) Comparison of egg period, hatching rate, and first-instar nymphs among three species of stonefly. Limnology 7 117-121.

YURISTA PM (1997) Bythotrephes cederstroemi diapausing egg distribution and abundance in Lake Michigan and the environmental cues for breaking diapause. J. Great Lakes Res. 23 202-209.

ZIAREK JJ, NIHONGI A, NAGAI T, UTTIERI M and STRICKLER JR (2011) Seasonal adaptations of Daphnia pulicaria swimming behaviour: the effect of water temperature. Hydrobiologia $661317-327$. 